\title{
DESARRAIGO Y ACCIONES ALTERNATIVAS AL DESARROLLO
}

J.Cristina Cifuentes Guerrero

Universidad Santo Tomás

\section{Resumen}

El presente artículo argumenta sobre la configuración deldiscurso del "desarrollo"durante el siglo XX y cómo éste se ha venido poniendo en tela de juicio como producto de las crisis económicas, aumento de la pobreza y progresivo deterioro del medio ambiente relacionados con la disfuncionalidad de los modelos impuestos entorno alcanzar el" desarrollo". En este sentido, este trabajo analiza los debates alrededor de la crisis civilizatoria y la modernidad, para enunciar que los modelos de desarrollo han provocado en los diferentes territorios distintas formas de desarraigo que impiden el sentido de pertenencia y tejido social en los diversos territorios y por el contrario los mantiene en un interminable circulo de marginación y pobreza. Por ello se sostiene, que es necesario dimensionar el desarraigopara interpretar las diferentes situaciones de marginación y vulnerabilidad de los territorios. De esta manera, se muestra, como acción alternativa al desarrollo, la perspectiva del "buen vivir", como apuesta contundente en la reconstrucción de los tejidos vitales rotos.

\section{Palabras Clave}

Desarrollo- crisis civilizatoria-desarraigo- Buen Vivir "SumakKawsay"modernidad

\section{Abstract}

The present article argues about the configuration of the discourse of "development" during the twentieth century and how it has come into question as a result of economic crises, increased poverty and progressive deterioration of the environment related to Dysfunctionality of the environment imposed models reach the "development". In this sense, the text addresses the debates around the civilization crisis and modernity, stating that the development models have provoked in the different territories a great phenomenon of uprooting that prevent the sense of belonging and social fabric in the different territories and On the contrary it keeps them in an endless circle of marginalization and poverty. Therefore, it is argued that it is necessary to dimension the uprooting to interpret the different situations of marginalization and vulnerability of the territories. In 
this way, the perspective of "good living" is shown as an alternative action to development, as a decisive bet in the reconstruction of broken vital tissues.

\section{Key words}

Development - civilizationcrisis - uprooting - Good Living "SumakKawsay" modernity

\section{Introducción}

Hoy en día los debates entorno al discurso de desarrollo, la crisis ambiental, la pobreza, eldecrecimiento económico, cambio climático y el territorio, demandan un cuestionamiento profundo en relación con los modelos hegemónicos que se han implantado de manera progresiva alrededor del mundo. Uno de ellos está ligado al consumismosin límitesen las sociedades modernas, ya que través de una producción capitalista orientada a la generación de deseoy creación de aspiraciones individualizadas, impone estilos de vida dependientes al mercado. Que olvida la dignidad de las personas sus derechos y de los de la naturaleza.

"La vida diaria de los habitantes de la gran metrópolis se ve influida por la necesidad de cultivar una actitud de indiferencia hacia los demás, a través de la búsqueda de señales de estatus, moda o signos de excentricidad individual" (Rodrígez Diaz, 2012)

Si se observa esta lógica, ha avanzado de manera devastadora en nuestra cultura e identidades, así como también en la apropiación de nuestros territorios. Los países de Latinoamérica en general se ven abocados a seguir dinámicas para el progreso y el desarrollo o como Escobar diría convertirnos en "locomotoras del Desarrollo"(Escobar, 2014, pág. 15).Las medidas impulsadas por el Banco Mundial y Fondo Monetario Internacional desde su creación han estado dirigidas a establecer reglas para las relaciones comerciales y financieras entre los países. El llamado consenso de Washington en 1989 planteó un conjunto de fórmulas para que los países en vías de desarrollo salieran de la crisis.Así mismo también la ONU creó una serie de comisiones económicas para impulsar el desarrollo de los países no desarrollados.

Pareciera como si todos debiéramos trabajar en pro de sostener un sistema hegemónico para "estar bien", por medio señalamientos de "expertos" (Banco Mundial, FMI, Naciones Unidas) en pro del "desarrollo", a través de discursos y recetarios que nos lleven alcanzar los ideales unidimensionales de leer y pensarse la realidad, como el crecimiento económico, el consumo infinito, la riqueza. 
Desarrollo, progreso y que, entre otras, ha generado la pérdida casi absoluta de nuestra identidad, de los valores colectivos, de la biodiversidad, de lo que significa territorio y felicidad para cada una de las comunidades existentes en el planeta.

Pero aun así "... la gran diversidad de luchas por defender paisajes, montañas, bosques, semillas, ríos, territorios, paramos; y por supuesto, otras formas humanas de construir el mundo son testimonios elocuentes de la crisis del Mundo: Moderno/Capitalista, secular, racional y liberal con su insistencia en la ilusión del "progreso" y el "desarrollo", en el que el consumo individual y la competitividad del mercado se convierten en la norma y medida del actuar humano..." (Escobar, 2014, pág. 21)

El inicio del siglo XXI está frente a un mundo globalizado que ha instaurado una fuerza devastadora y unidimensional de concebir el territorio desde una sola fuente de poder, una sola manera de producir, comerciar y consumir con unos determinados y controlados canales y medios de comunicación, todo lo cual está implicando la negación de la vida y la dignidad.(Lozano, 2012)

El proceso de apertura neoliberal que se impone con el reciente discurso del desarrollo está acompañado de presiones de carácter económico, político, militar y religioso, generando en las naciones unos procesos de desarraigo y ruptura con los lazos vitales, que llevan un poco a que estas poblaciones sean invadidas, violentadas, desprestigiadas en sus costumbres, entre otras diciéndoles que son "subdesarrolladas".

Por ello, resulta importante analizar las formas, dimensiones y características del desarraigo que generan las situaciones de marginación, vulneración de derechos y empobrecimiento de las personas y las comunidades. Desde dicho análisis se sostiene, en este escrito, que la mencionada situaciónno es producto del subdesarrollo o falta de desarrollo, sino es el resultado de diferentes procesos de desarraigo o rupturas con los lazos vitales con el territorio, a los cuales ha estado sometida en generalla dinámica de vida planetaria.

Con el propósito de argumentar la anterior afirmación el artículo en primer lugar abordará el discurso sobre el desarrollo y cómo este, se ha venido poniendo en tela de juicio. Posteriormente se explica el concepto de desarraigo como propuesta de perspectiva de análisis para interpretar las diferentes situaciones de marginación y vulnerabilidad de los territorios y finalmente desde la perspectiva del buen vivir, se intentará mostrar la importancia de la reconstrucción de los tejidos vitalesrotos que sirve como alternativa al desarrollo. 


\section{El discurso del "desarrollo" en tela de juicio}

A lo largo del presente apartado, se pretende recopilar y sintetizar los hechos históricos más significativos del siglo $X X$ que contribuyeron a posicionar el discurso del "desarrollo" y ha servido como mecanismo para la imposición de modelos económicos, políticos y socioculturales que han acentuado las situaciones de marginación, vulneración de derechos y empobrecimiento de las personas en general.

Al finalizar la primera guerra mundial en 1918, los países europeos quedaron devastados, situación que favoreció a los Estados Unidos ya que esto les permitió convertirse en el principal prestamista y proveedor de materias primas, productos alimenticios e industriales de estos países consolidando en los años de 1920 laindustria eléctrica, química y petroquímica, la aeronáutica, el cine y la radiofonía.(López, 2009)

El modelo económico que imperaba en esta época estaba inspirado por la corriente de pensamiento clásica, de los cuales se destacan entre otros, personajescomoAdam Smith, DavidRicardo,Taylor. Ello permitió la implementación de un sistema económico basado en la producción industrial en serie (fordismo) bajo la premisa de la "mano invisible del mercado" que mantendría el equilibrio entre la oferta y la demanda y a su vez un crecimiento económico constante.

Europa con el respaldo de EEUU pudo invertir en obras públicas y empresas bajo el modelo de estandarizacióny producción en masa, lo cual generó un crecimiento económico en los "dorados años veinte" principalmente en los EEUU. "La economía mundial se recuperó, favorecida por la política. Pero se puede afirmar que los Estados Unidos tuvieron una clara recuperación, producida por el consumo de electrodomésticos y el automóvil. El resto de los países solo tuvo una ligera recuperación..."(López, 2009)Solo hasta 1925 Europa pudo vivir prosperidad económica ya que la guerra finalizó en algunas partes, Europa Oriental y Asia continuaron en diferentes conflictos bélicos que duraron casi hasta 1924 (Vincent J., 1979).Con las orientaciones estadounidenses se adoptó el nuevo sistema financiero, pero pronto este modelo fordista de liberalización económica entraría en crisis.

Pronto la sobreproducción, la especulación, la pérdida de poder adquisitivo y el desempleo, generaron una gran caída de los precios. La desigual y relativa recuperación económica y la especulación que inicia con la quiebra de la Bolsa de Nueva York más conocido como el Crack del 29, puso al desnudo las 
imperfecciones del liberalismo económico; los monopolios que habían concentrado excesivamente las riquezas, la superproducción que desvalorizó los productos industriales y agropecuarios, la caída de los valores de las bolsas, y la desocupación que crecía como consecuencia de la gran depresión.(Pradenas Fierro, 2008)Las grandes industrias ya no tenían más mercado que abarcar y necesitaban nuevos nichos.

Esto provocó un efecto dominósobre el resto del mundo,quedando la época conocida como "La gran depresión": el desempleo creció en amplias proporciones, las personas se vieron imposibilitadas a devolver los prestamos adquiridos, la caída de los créditos afectó la financiación de la industria y limitó el consumo que a su vez provocó un cierre de una gran úmero de empresas. “...En 1932 en todo el mundo había 40 millones de desempleados..."(López, 2009)

La gran depresión avivaba los conflictos especialmente en Europa, principalmente en Alemania con el surgimiento del nazismo y en Italia con el fascismo.El grado de miseria y la esperanza que representaron para estos pueblos estos ideales, desataron la segunda guerra mundial entre los años de 1939 a 1945. Además,cabe mencionar que la economía estadounidense se encontraba en quiebra por ende aumentó la presión por la devolución de los préstamos que había otorgado a los países europeos.

En este contexto empieza a tomar gran relevancia la línea de pensamiento desarrollada porKeynes quien "....argumenta la defensa de programas económicos que ya estaban ensayando en el Reino Unido y en Estados Unidos por el presidente Frank Rooselvelt. Keynes propone la inexistencia de mecanismos de ajuste automáticos que permitan a la economía recuperarse de las recesiones, afirmaba que el ahorro no invertido prolonga el estancamiento económico...por lo tanto el gasto público debe compensar la insuficiente inversión privada durante una recesión..."(López, 2009, pág. 12)

El programa de gobierno "New Deal" que se instauró en los Estados Unidos en el año de 1932 tuvo como fin poner en marcha la economía a través de la inversión en obras públicas.Fue así como el presidente Frank Rooselvelt se destacó por brindar empleo a las personas en la construcción de escuelas, calles, parques de recreación, incentivó la construcción de complejos industriales, fijó salarios mínimos. Sin embargo, dichos programas adoptados no solucionaron directamente la crisis económica de los EEUU, sino hasta su intervención en la segunda guerra mundial que fue lo que realmente logró movilizar su economía.(López, 2009)

Al finalizar la segunda guerra mundial, las potencias anteriores (Francia, Italia, Alemania, Inglaterra y Japón)estaban destruidas y eclipsadas, lo cual permitió que 
se fraguará el nuevo orden económico mundial, que dio inicio a través de la Conferencia de Bretton Woods en 1944 en los Estados Unidos. Como producto de dicho interés se crea en 1946el Fondo Monetario Internacional (FMI) y el Banco Mundial (BM).

“...En este punto, es necesario considerar además, que la necesidad de establecer un nuevo orden financiero mundial, abierto al comercio e inversiones (principalmente de Estados Unidos y Gran Bretaña) y respaldado por la estabilidad monetaria, surgía también como reacción a ciertos incipientes rasgos de independización que se habían manifestado de... los países pobres (que) habían comenzado a desarrollar una industria interna para sustituir los artículos que anteriormente se importaban... Existía, por lo tanto, cierta alarma en las potencias occidentales por detener estos procesos...y la necesidad de volver a encauzar las actividades económicas mundiales dentro de los marcos del comercio internacional donde tradicionalmente habían consolidado sus posiciones de poder..."(Reyes Konings, 2010, pág. 74)

También se configuró un nuevo orden político internacional, dos bloques en el mundo, uno en cabeza de los Estados Unidos "Bloque capitalista" el cual promovió el modelo económico de libre mercado y la democracia representativa y el "Bloque Socialista" en cabeza de la Unión Soviética el cual planteó que la economía debe ser planificada y determinada por objetivos sociales prioritarios.(Contreras Plata, 2004)

Los Estados Unidos para evitar un acercamiento por parte de los países europeos y Japón a la Unión Soviética idearon el "Plan Marshall" en el año de 1947 que consistió básicamente en apoyar la reconstrucción económica de estos países por medio de inversiones millonarias con la finalidad de promover la adopción del modelo de libre empresa y ampliación del mercado.

Pues bien, a partir de esta en época, especialmente desde la posesión del Presidente de los EEUU Harry S. Truman (1945-1953), el mundo es dividido en países desarrollados y subdesarrollados y como algunos teóricos(Max-Neef, Elizalde, \& Martín, 1986),(Escobar, 1989);(santos, Vasconi, Kaplan, \& Jaguaribe, 1969);(Morande, 1987)lo han mencionado se da inicio a la era del "desarrollismo".

Desde una perspectiva crítica, EEUU necesitaba apalancarse de alguna manera, ya que venían de una fuerte crisis económica.Y si nos preguntamos cómo lo hicieron después de una posguerra y en medio de una crisis del modelo liberal, fue mediantela "occidentalización del mundo",es decir induciendo a los países del 
"Tercer mundo" 1 de adoptar sus modelos de estilo de vida para abrir nichos de mercados y reactivar sus economías estancadas. Es así como toma gran relevancia el discurso de posesión del presidente Truman del 20 de enero de 1949 en los Estados Unidos de América,posterior a la finalización de la segunda guerra mundial y concordante al discurso de modernización y el claro interés de los países imperialistas de salvaguardar el sistema capitalista.

“...Truman planteó la necesidad de implementar políticas de desarrollo para que los países menos avanzados pudieran alcanzar el estándar económico y cultural de occidente. Es así como el "desarrollo" cobra relevancia y gracias a su enorme capacidad de seducción se convirtió en un dispositivo discursivo capaz de modelar la realidad. Por ello, tras las palabras del "presidente", automáticamente los países de Asia, África y América Latina se convirtieron en "subdesarrollados..."(Deniz, 2012)

A partir de los años 50, el camino trazado para resolver las diferentes problemáticas sociales sería por medio del crecimiento económico, la industrialización y adopción de modelos de las sociedades "desarrolladas" e industrializadas, pues todo ello en teoría permitiría la superación de la pobreza y desigualdad social.

El discurso ${ }^{2}$ de desarrollo trajo consigo una manera universal de entender el mundo así: a nivel político económico, la idea de formación de capital entorno a la política monetaria y fiscal para el crecimiento económico, y en el aspecto cultural se impone como única fe la ciencia, el progreso y la razón con la adopción de un sistema de educación con los valores implícitos de modernización, industrialización y urbanización(Jimenez Masullo, 2010).

Así pues, con la necesidad de los países industrializados de ampliar sus mercados, se dio forma al discurso del desarrollo mediante aparatos de producción de conocimiento como: el Banco Mundial, Naciones Unidas, Fondo Monetario Internacional y demás agencias de planeación y desarrollo. Estas establecieron una serie de recetarios que los países subdesarrollados deberíanseguir para alcanzar el crecimiento económico, progreso y desarrollo.

Por su parte la ONU creó una serie de comisiones económicas para impulsar el desarrollo de los países no desarrollados, en el caso de América Latina la

\footnotetext{
1“"Tercer Mundo fue acuñado por primera vez por el demógrafo francés, Alfred Sauvy, a comienzos de los años cincuenta para referirse a las áreas pobres y atrasadas del mundo, siendo su uso una analogía del -Tercer Estado francés. En la nueva configuración geopolítica del sistema internacional que empezaba a configurarse en la segunda post-guerra, el Tercer Mundo representaba a las naciones pobres y no industrializadas, el Segundo a las naciones industrializadas comunistas, y el Primer Mundo a las naciones industrializadas libres..."(Jimenez Masullo, 2010)

2 Entiéndase este concepto tal como lo ilustra(Foucault, Politics and the Study of Discourse, 1991)
} 
organización más representativa y que actualmente opera es la Comisión Económica para América Latina y el Caribe CEPALcreada en el año de 1952, que promovió la implementación del modelo de industrialización por sustitución de importaciones, ISI.

Así, la tendencia desarrollista instauró que los estadossubdesarrollados deberían promover políticas económicas que impulsen la industrialización, para alcanzar una situación de desarrollo autónomo. Se destaca dentro de esta tendencia en América Latina,pensadores comoFurtado y Prebish, que fueron actores decisivos desde la CEPAL en la formulación de políticas socioeconómicas para el "desarrollo" enfocadas principalmente en la industrialización porsustitución de importaciones (ISI).

Recogiendo algunos de los planteamientos de Escobar, se puede comprender cómo Estados Unidos se constituye como una de las potencias que más beneficios recibió como resultado de la implementación de políticas para el desarrollo y subdesarrollo, pues estas le sirvieron como estrategia para expandir los mercados de los productos norteamericanos, controlar las materias primas, consolidar el centro y encontrar ganancia en el exterior(Escobar, 1995) junto con esta estrategia y el aparato de conocimiento generado, igualó la noción de desarrollo a la de crecimiento económico.Este momento histórico Escobar lo caracteriza “...La teoría de la modernización en las décadas de los cincuenta y setenta, con su teoría aliada de crecimiento económico..."(Escobar, 2014, pág. 27).

En América Latina, a inicios de la década de los 60 el modelo de exportación de materias primas a los países ricos e industrializados del primer mundo, promovido por la CEPAL, entra en fuertes cuestionamientos, por parte de los mismos analistas pertenecientes a la Comisión, en vista del estancamiento socio económico y aumento de la pobreza en el que se encontraba los países del sur.

Los científicos sociales de esta época como (Prebisch, 1951), (Furtado, 1971)entre otros,explican dicho estancamiento a través de lo que denominaron "la teoría de la dependencia", la cual tiene como argumento central, que las relaciones comerciales con los países del norte son desiguales y generan subordinación, no solo deíndole económica sino también política y cultural.

Se puede inferir que uno de los argumentos del por qué poner en tela de juicio el discurso del "desarrollo", se encuentra precisamente en las críticas surgidas con la teoría de la dependencia, pues esta corriente de pensamiento planteó situaciones como, el que las naciones pobres asumieran únicamente un rol deproveedor a las naciones ricas de sus recursos naturales. 
Así en América Latina se consideró que las políticas socioeconómicas de la época “...necesitarían realizar un considerable esfuerzo de capitalización para acelerar su desarrollo económico... (Por medio de) ...la sustitución de ciertas importaciones por la producción interna a fin de que puedan crecer otras importaciones..." (Prebisch, 1951, pág. 3)es decir, estas medidas se enfocaron en fortalecer la industria interna a través de un sistema impositivo que permitiera el mejor aprovechamiento de los recursos disponibles.

Sin embargo, los países "desarrollados" no dejaron de tomar ventaja sobre los países de Latinoamérica, Asia y África, pues fue ampliamente difundido e implantado la idea que sugiere, como principal limitante de los países subdesarrolladoses, el bajo nivel de formación de capital y la baja capacidad de ahorro e inversión induciendo como única salida acudir a la ayuda externa. Lo anterior, sirvió “...para justificar las masivas transferencias de capital y asistencia tecnológica que corrían desenfrenadamente de las naciones desarrolladas a las subdesarrolladas..."(Jimenez Masullo, 2010, pág. 33)convirtiéndose estos en un destino ideal para tecnología obsoleta y para los grandes empresarios, la rentable oportunidad de conseguir mano de obra barata para reducir costos en producción.

La industrialización se convirtió entonces en un elemento de gran importancia para todos los países, creándose así una economía altamente dependiente al petróleo, especialmente en los Estados Unidos y Japón “...Entre 1945 y finales de los 60, Occidente y Japón consumían más petróleo que nunca. Sólo en Estados Unidos, el consumo se había duplicado entre 1945 y 1974. Con un $6 \%$ de la población mundial, Estados Unidos consumía el 33\% de la energía de todo el mundo. Al mismo tiempo, la economía estadounidense mantenía una cuarta parte de la producción industrial mundial, lo cual quiere decir que los trabajadores estadounidenses eran cuatro veces más productivos que la media global, pero a cambio el país consumía cinco veces más energía..." (Blinder, 1979)

La economía mundial entró en recesión en los años 1970 y continuó en principios de losaños 80, los precios del petróleo se dispararon generando la Crisis del petróleo de 1973, se creó un punto muerto para la mayoría de los países de la región. Los países en vías de desarrollo se encontraron en una desesperada crisis de liquidez.

La crisis de los años 70 demuestra nuevamente lo insostenible que resultaron las políticas crecimiento económico, ya que estas no fueron directamente proporcionales al ideal de desarrollo como bienestar para los países "subdesarrollados", antes, al contrario, las brechas de desigualdad social crecían aún más. 
La teoría del evolucionismo trabajada principalmente por Schumacher (1973) que había igualado el concepto de "evolución" con el de "desarrollo", situó a los países no industrializados en situación de atraso, para ello requerirían evolucionar, modernizarse para desarrollarse, es decir como una serie de etapas para alcanzar el primer mundo rico, civilizado y feliz.(Galeano, 1997). En el caso agrícola con la llamada "revolución verde" se establece la idea de implementar políticas tendientes a acrecentar la productividad de los países en desarrollo a partir de la modernización de prácticas tradicionales de cultivo.

Dichas prácticas algunos autores como (Wallerstein, 1979), lo atribuyen al sistemamundial capitalista, que ha subordinado a los países de la periferia al centro imperialista y acumulador, es decir redistribuyendo los recursos de la periferia al centro, su tesis pone en cuestión la supuesta bondad del desarrollo económico a través del comercio internacional.

Así, como producto de los tropiezos de la economía con respecto a las políticas enfocadas exclusivamente en el crecimiento económico y su fracaso para lograr el desarrollo, surgieron apuestas como las planteadas por (Sen, 1999)quien concibe que además de promover el crecimiento económico se debe paralelamente expandir las libertades de los individuos, pues califica este factor como determinante para alcanzar el desarrollo.

Desde esta perspectiva "lo que pueden conseguir positivamente los individuos depende de las oportunidades económicas, las libertades políticas, las fuerzas sociales y las posibilidades que brinda la salud, la educación básica, el fomento y cultivo de las iniciativas (es decir,) la expansión de las libertades y derechos también contribuyen muy eficazmente al progreso económico."(Sen, 1999, pág. 4)

En este mismo sentido,(Max-Neef, Elizalde, \& Martín, 1986)atribuyen el fracaso del desarrollismo a la incapacidad del sistema de controlar los desequilibrios monetarios-financieros y la falta de entendimiento de los diferentes contextos en las cuales se aplican las recetas para el crecimiento económico, por ello proponen que el desarrollo se concentra y sustenta en la satisfacción de las necesidades humanas fundamentales, la generación de niveles crecientes de auto dependencia, la articulación orgánica de los seres humanos con la naturaleza y la tecnología, con los procesos globales y locales así como también de la sociedad civil y el Estado.

Pues bien, este artículo quiere mostrar un claro desacuerdo frente a la obsesión por el crecimiento económico legitimado a través del discurso del desarrollo, que solo continúa intentado mezclar elementos incompatibles, como, por ejemplo, el crecimientoeconómico y la sostenibilidad ambiental; crecimiento económico y libertad; crecimiento económico y erradicación de la pobreza. 
“...El discurso del desarrollo ha colonizado la realidad de tal manera que inclusive sus oponentes se han visto obligados a plantear sus críticas en los mismos términos desarrollistas...De ahí la explosión de apellidos del desarrollo: humano, participativo, endógeno, sostenible, etc. Esta profusión de apellidos, acompañados a su vez de múltiples intentos fracasados en la práctica de escapar al discurso convencional del desarrollo, es evidencia del poder de dicho discurso, fundamentado en el núcleo duro del economicismo..." (Jimenez Masullo, 2010, pág. 44)

Por esto se considera que el desarrollo debe ponerse en tela de juicioporque a pesar de los múltiples apellidos que se han integrado a su discurso, estas tendencias continúan al servicio del discurso de la modernidad y desarrollo, para el crecimiento económico y en definitiva no son funcionales para la diversidad de comunidades que entienden e interpretan el mundo de manera totalmente diferente, pues este afán por el desarrollo solo"... ha contribuido a debilitar las políticas sociales, las posibilidades de acceso de los grupos pobres a los servicios básicos, ha concentrado los beneficios que brindan las oportunidades de las medidas pro-crecimiento, es desolador en muchos sentidos: mercado en unos pocos grupos, de modo que si antes no fueron claras las ventajas del Estado, ahora no son claras las ventajas del mercado..." (Bejarano, 2010)

Como se puede observar el discurso de "desarrollo" se ha configurado como un dispositivo de poder a lo largo de la historia, el cual ha mantenidoy mantiene un sistema económico en beneficio de una pequeña parte de la población mundial, sin dar cabida al pluriverso de vida existente que podría tener maneras más sensatas y menos dañinas para vivir bien en este planeta.

“El desarrollo, en tanto propuesta global y unificadora desconoce de una manera violenta los sueños y las luchas de los pueblos subdesarrollados, muchas veces por la acción directa de las naciones consideradas como desarrolladas...Es más, dicho estilo de vida consumista y depredador está poniendo en riesgo el equilibrio ecológico global y margina cada vez más masas de seres humanos de las (supuestas) ventajas del ansiado desarrollo..."(Acosta, 2012, pág. 34)

\section{Desarraigo y crisis civilizatoria}

“Quizá necesitamos crear una sociedad Basada en la calidad y no en la cantidad, En la cooperación y no en la competencia" (Latouche, 1993, pág. 85) 
Como se observó en el capítulo anterior, el mundo ha mirado a Latinoamérica, Asia y África como“subdesarrollados”. Incluso comoéstos se miran a sí mismos, diciendo entonces que no tienen determinado desarrollo industrial, que no son tan competentes, que requieren de inversión extranjera, etc. Sin embargo, lo que aquí se plantea no es que estamos frente a un cumulo de países subdesarrollados y en atraso,sino que nos encontramos frente a unos procesos de desarraigo que han propiciado la gran brecha de desigualdad y miseria en la que se encuentra gran mayoría de territorios del planeta. Por lo tanto, para efectos de este análisis, el problema no gira en torno al subdesarrollo sino al desarraigo producto de la crisis civilizatoria del siglo XXI.

Este capítulo ofrece una reflexión teórica acerca de la crisis civilizatoria actual y proponeuna perspectiva de análisis del territorio, que coloca comoeje central el concepto dedesarraigo,con el objetivo de mostrar algunas categorías y variables que serían importantes considerar paradimensionar este fenómeno latente en los territorios marginados.

"...La noción de crisis civilizatoria es importante porque con ella se quiere enfatizar que estamos asistiendo al agotamiento de un modelo de organización económica, productiva y social, con sus respectivas expresiones en el ámbito ideológico, simbólico y cultural..."(Vega Cantor, 2009).Es decir, estamos asistiendo un aumento generalizado de las hambrunas, las guerras, el desempleo, miseria, desigualdad y pobreza en el mundo, producto de la acumulación excesiva de riqueza por parte de unos pocos sectores, la devastación de los recursos naturales y la implementación de modelos económicos capitalistas para el "desarrollo" de la sociedad en general.

El modelo de organización económica que por excelencia ha predominado en occidente, es el capitalismo, cuyo eje fundamental es la expropiación o proceso de despojo de cada uno de los ámbitos de la vida del ser humano, como: la tierra y bienes comunes (naturaleza), del cuerpo de seres humanos para someterlos en sus propios territorios, del producto del trabajo de artesanosy campesinos, del tiempo y de sus costumbres, de sus saberes entre otros.(Vega Cantor, 2012)

Por ello este textoatribuye la crisis civilizatoria en el siglo XXI al agotamiento del modelo capitalista, en vista de que este ha sido uno de los sistemas más predominantes en occidente y en todo el discurso de la modernidad y progreso.

En este sentido resulta pertinente abordar el análisis del profesor Renán Vega(2012) para entender los alcances del modelo capitalista actual,desde sus diferentes procesos de expropiación o despojo, que a continuación se resumen: 
1. El proceso de expropiación de la tierra y bienes comunes, como uno de los principales medios de acumulación capitalista, se vale de la expulsión directa de las comunidades de sus territorios a través del aumento de las rentas privadas y la puesta en venta de manera masiva las tierras. Pues este mecanismo de acumulación de capitalquelogra" ...descolectivizar la reproducción de la fuerza de trabajo e imponer el uso más productivo del tiempo libre..."(Vega Cantor, 2012, pág. 36)garantiza el sometimiento de los desposeídos a las condiciones de trabajo asalariadoquelos dueños de las tierras quieran ofrecer, así como tambiéndebilita de sobre manera,la capacidad de resistencia de una comunidad.

Un caso observable en relación a este tipo de expropiación es el caso colombiano específicamente en la Región Pacifica, en la cual se registra el mayor número de desplazamiento de población indígena y negra, pues se ha atribuido una clara relación entre el conflicto armado y los intereses de grupos económicos por establecer proyectos agrícolas, pesqueros, mineros, de explotación de la palma aceitera entre otros en vista de que esta es un área especial con gran biodiversidad. (Agudelo, Carlos Efrén, 2001)

2. El proceso de expropiación del cuerpo de seres humanos para someterlos en sus propios territorios, se refiere a como el cercamiento de las tierras y bosques impiden el disfrute libre y de las cualidades de un territorio, pues dicha dinámica va en contra de las tradiciones y prácticas cotidianas de la vida en comunidad. La propiedad privada de la tierra elimina la diversidad productiva de los territorios, pues estos deben sustituirse por agricultura o ganadería que son más rentables para la acumulación. “...Así mismo el cercamiento paralelo de las mentes y de la imaginación, que provoca que estos cercamientos sean definidos y percibidos como una forma de progreso humano universal y no de crecimiento de los privilegios y los derechos excluyentes de unos pocos a costa del desposeimiento y el empobrecimiento de muchos..."(Vega Cantor, 2012, pág. 46).

En el caso colombiano dicho proceso de expropiación puede ser observado a gran escala en las zonas rurales del país donde miles de campesinos han tenido que migrar a las ciudades, en vista de que multinacionales y grandes propietarios han dispuesto la tierra para monocultivos como el café, el plátano, la palma aceitera, la agricultura, ganadería entre otros, que responden precisamente a dinámicas del mercado y del consumo de las urbes, sin tener en cuenta los efectos que genera en la productividad de la tierra. 
3. La expropiación del producto del trabajo se refiere a cómo los trabajadores dejan de ser lo poseedores de los materiales con los que elabora un objeto, así como también del producto acabado resultado del uso de sus saberes. “...en pocas palabras el trabajo alienado está relacionado con el hecho de que el trabajador ha sido expropiado y ya no puede disfrutar de un proceso que le es ajeno y cuyo producto no le pertenece, porque ha sido apropiado por otro, por el capitalista..."(Vega Cantor, 2012, pág. 118).Pues vemos hoy en día una sociedad avocada a un estilo de trabajo alienante en las empresas en donde venden su fuerza de trabajo, cada día más desligado de la vida en familia, comunitaria y solidaria. Prevalece la competencia y la mayor parte de estas personas vuelve su único círculo social más cercano, sus compañeros de trabajo, las relaciones familiares son nefastas y comunitariamente hablando su participación, interés y apropiación de su entorno son casi nulas.

En consecuencia, vale la pena señalar los rasgos que definen la labor de un artesano como muy bien lo describe el profesor (Vega Cantor, 2012, pág. 124) y entender un poco la brecha en lo que ha significado la expropiación del producto del trabajo. La labor de un artesano que es también una forma alternativa de vida la cual se caracteriza por la responsabilidad en el trabajo, la recompensa asociada no a una remuneración sino al trabajo mismo, autocontrol en el proceso laboral, la pericia que adquiere con la práctica, la labor intelectual está ligada a la actividad material, el trabajo vivo es una fuente de experimentación y lo más importante el trabajo del artesano no es una actividad individual puesto que confluyen la familia y la comunidad.

En este sentido, lo que ha significado la expropiación del trabajo es la progresiva devaluación de la labor de un artesano, siendo está calificada como situación de atraso,paraavanzar hacia el "progreso". Parair un poco más allá de los efectos del capitalismo, se quiere mencionar que este fenómeno se debe fundamentalmente al discurso contemporáneo impuesto de la "modernidad y progreso", que ha puesto casi que cualquier práctica de antaño como algo que se debe superar e "innovar".

4. La expropiación del tiempo de los trabajadores en el mundo actual es nefasta, si se observa que por medio de la tecnología se aliena las mentes y tiempo, para que estáspersonassolo trabajen en función del sistema capitalistaenaras de la modernidad y progreso. Es decir, no se quiere estigmatizar las herramientas tecnológicas, pero sí poner en punto crítico cómo estos recursos han sido utilizados por los discursos sobre 
"modernidad y progreso" para destruir los lazos más vitales comunitarios, como lo es el contacto directo con las personas que rodean a diario nuestro entorno.

Por medio de la tecnología, hoy en día las grandes empresas capitalistas han logrado potencializar en niveles nunca antes vistos la apropiación del tiempo ajeno y ejercer un control al detalle de sus trabajadores. “...En el mundo contemporáneo, la expropiación del tiempo se ha extendido a todos los ámbitos de la vida y no se limita como antes, al terreno laboral. En el capitalismo actual, la expropiación del tiempo de la vida, se expresa de manera paradójica en la falta de tiempo. Esto es ocasionado por el culto a la velocidad, la aceleración de ritmos..."(Vega Cantor, 2012, pág. 164)

5. La expropiación de saberes tiene que ver fundamentalmente a que el sujeto ha sido expropiado de su memoria, costumbres, hábitos, religiosidad, cosmovisión quedando reducido a un mero consumidor "... que vive en un presente eterno, sin antes ni después..."(Vega Cantor, 2012, pág. 187), es decir, desarraigado de la vida, pasando a ser dependiente de las dinámicas del consumo impuestas por el mercado y el sistema mismo.

El ejefundamental del sistema capitalista es el incremento de la productividad en el menor tiempo posible y el desarrollo de la industria ha contribuido en dicho propósito, pues convirtió al artesano en un apéndice de la máquina,el cual realiza determinadas y definidas labores que ha conllevado a la atomización de los saberes de los antiguos artesanos. Hoy en día reina la separación de la teoría y la práctica que es muestra ni más ni menos sino la extracción del saber obrero, de su experiencia y cultura técnica por un "departamento pensante".(Vega Cantor, 2012)

A pesar del análisis realizado de manera brillante por el profesor Renán Vega sobre el modelo capitalista operante, este texto busca trascender de dicho modelo, pues esta crisis civilizatoria va más allá de un sistema que acumula en exceso capital y es el discurso de la "modernidad y el progreso", que de alguna manera se ha instaurado de manera hegemónica sobre los diferentes modelos económicos en el mundo.

Por ello, es esencial entender cómo este modelo capitalista, a través de sus diferentes maneras de expropiación, se han fortalecido a travésdel discurso de la "modernidad". La crisis civilizatoria entonces,estáasociada al avance progresivo de una cultura consumista,extractivista y destructora de lazos comunitarios. 
En este sentido, Renán Vega hace una gran contribución al alertarnos como la nueva civilización está alienada de la "modernidad", al punto que no se logra tener conciencia del abismo al que se acerca el mundo contemporáneo, debido al "pensamiento moderno" que ha encapsulado las mentes e invisibilizado todas aquellas comunidades, territorios, naturaleza y personas que no comparten estas visiones unidimensionales de la realidad.

En el caso colombiano los efectos que tuvieron las políticas externas de los países "Desarrollados" asociados al modelo capitalista neoliberal y discurso modernizanteen la región son bastante desalentadores, ya que desde hace 70 añoseste país se encuentra en un contexto de violencia el cual arroja una cifra de más de "siete millones de personas que se han visto forzadas a desplazarse dentro y fuera del territorio nacional, abandonando sus hogares, sus tierras y territorios, sus bienes, sus costumbres, sus comunidades y sus formas de vida"(REGISTRO ÚNICO DE VÍCTIMAS (RUV), 2017). Ya quese han venido ejerciendo diferentes tipos de dominios territoriales lo cual ha traído consigo una cantidad de hechos violentos y vulneración de los derechos y dignidad de sus habitantes por las disputas de estos territorios.

La implementación del modelo capitalista neoliberal en Colombia ha implicado diferentes procesos de despojo y expulsión de la población,“...su expulsión sistemática obedece, entre otros factores, al interés de los grupos armados y otros actores por apropiarse de los recursos naturales y del subsuelo o simplemente para consolidar las rutas y corredores estratégicos del negocio de la droga..."(Centro Nacional de Memoria Histórica, 2015, pág. 38).Pues bien mediante esta estrategia históricamente se ha logrado la imposición de recomendaciones externas, paulatinamente nuestros territorios se convirtieron en propiedades de terratenientes con grandes monocultivos para exportar materia prima al "primer mundo", territorios ideales para la inversión extranjera en especial para la extracción de recursos naturales, la entrada del narcotráfico como parte de los negocios mundiales, han venido sometiendo a las comunidades habitantes de los territorios en dinámicas de desigualdad, inequidad e injusticia social.

“...Desde una perspectiva nacional, el desplazamiento forzado ha resultado funcional a intereses rentistas que se han beneficiado de modelos de desarrollo que han ignorado los efectos de la guerra, y que, al hacerlo, han tenido un efecto excluyente, inequitativo, concentrador y discriminatorio..."(Centro Nacional de Memoria Histórica, 2015, pág. 28)

Esta dinámica ha provocado el fenómeno de desarraigo que se entenderá como lo señalaLozano "...como un proceso de rupturas complejas producidas en el ser y el hacer de personas, grupos y comunidades dentro de estrategias de subyugación y 
sometimiento..."(Lozano V., 2009, pág. 295)en el cual el territorio es entendido como el principal espacio en el que las diferentes comunidades guardan una relación simbólica y afectiva que implica lazos sociales en un determinado espacio o lugar.

El territorio es fundamentalmente un escenario de conflictividad en los cuales se manifiesta relaciones de poder que surgen de las dinámicas sociales, que a su vez tienen que ver con diferentes clases de pensamientos, conceptos, teorías, ideologías y cosmovisiones.Mançano(2012) caracteriza el territorio desde su multidimensionalidad, compuesto de diferentes escalas geográficas y espacios que develan tipos de gobernanza y propiedad. Pues la forma de relacionarse cada uno de los seres humanos, las comunidades van ser fundamental para comprender la conflictividad y relaciones de poder en juego en la lucha por un determinado territorio.

De acuerdo con lo expuesto por (Lozano, 2012) el territorio se ordena a partir de cuatro perspectivas que define así:

1. Tierra $\rightarrow$ lo cual hace referencia al espacio geográfico y demás elementos bióticos y abióticos constituyentes del planeta.

2. Terreno $\rightarrow$ Que se define como el campo de acción humana en el cual el ser humano le da diferentes usos a la tierra

3. Territorio $\rightarrow$ que va significar la interacción de los poderes a partir de las relaciones de enfrentamiento entre sujetos que se mueven en el espacio

4. Terruño $\rightarrow$ referido al sentido de pertenencia a un espacio o lugar, lo cual se vincula a una historia y a un tipo de espiritualidad con el territorio.

Desde esta perspectiva el territorio como espacio donde se ejerce un poder y dominio va asumir caracteres de acuerdo con las relaciones conflictivas dentro del mismo de índole política, económica, social, cultural, simbólica, entre otras. Pues el territorio es básicamente una construcción social que parte del ejercicio de poder cuando se nombran cada uno de los espacios. Lozano (2012)señala entonces que este debe ser comprendido como un espacio intersubjetivo, en el cual se manifiesta la una confluencia de intencionalidades en juego alrededor de múltiples intereses.Es por ello que una de las características fundamentales del territorio es la complejidad, debido a que todos los elementos están en interdependencia en donde se manifiesta una realidad de múltiples relaciones que se afectan unas con otras.

La intencionalidad de los sujetos dentro del territorio es lo que convierte este en un sistema complejo, ya que es incierto e incontrolable la manera en la cual ordenan el territorio a partir de las disputas de intereses o intencionalidades que se juegan a 
través de discursos legitimadores de las relaciones de poder. Es fundamental entender que estos sujetos siempre van a estar en la lucha por la posibilidad de soberanía por medio de la permanente construcción y deconstrucción de las territorialidades.

En este sentido los procesos históricos son el resultado de la construcción y deconstrucción permanente de territorialidades que van llenando de cargas de significación los lugares, que se estructuran desde imaginarios que han sido construidos a partir de cosmovisiones y formas de apropiación del territorio. Lozano(2012) explica que una de las formas fundamentales de construcción de territorialidades son los procesos de conquista territorial, que implica un proceso de invasión caracterizado por estrategias como exploraciones de reconocimiento, para identificar los recursos, identificación de posibles aliados para generar expresiones de poder y así finalmente lograr arrasar con el poder existente.

Pues bien este fenómeno de conquista territorial en el caso Colombiano se puede constatar con la implantación de agroindustrias (como por ejemplo el de la palma africana), construcción de carreteras, monocultivo extensivo del banano, extracción de oro, materiales de construcción, implantación de ganadería extensiva, la explotación de petróleo que ha dejado como resultado una economía de expansión y grandes cinturones de miseria .Como lo señala (Castells, 2007), el modelo de desarrollo neoliberal en Colombia ha dejado en manos del mercado y del crecimiento los avances sociales, estancándolos y favoreciendo a los empresarios.

Sin embargo, la crisis civilizatoria que se quiere señalar consiste en que el sistema actual moderno y progresista, ha generado dinámicas de apropiación devastadoras por parte de agrupaciones económicas de tal forma en los territorios del planeta, que ha producido un fenómeno generalizado de desarraigo, arrasando con la interculturalidad y formas de relacionarse en sus lugares.

“...el fenómeno de desarraigo actual constituye un punto culminante y la expresión contemporánea de un proceso de estructuración social -en otros términos, de construcción de territorios- caracterizado por la imposición de modelos económicos y políticos colonizantes, inequitativos, discriminatorios, que han exigido el sometimiento de las mayorías y que, poco a poco, han ido copando los espacios de libertad que los grupos empobrecidos (indígenas, negros, campesinos, obreros, pobladores urbanos) en cada época habían ido creando. En otras palabras, estamos ante la reproducción de las campañas de sometimiento de los cimarrones y de invasión y expropiación de los territorios indígenas, en sus herederos étnicos y sociales..."(Lozano V., 2009, pág. 296) 
Desde esta perspectiva para dimensionar el fenómeno de desarraigo, que se lee como la ruptura de tejidos vitales con dinámicas asociadas a la vida misma como: la recreación, la educación, el trabajo, la participación y organización comunitaria, la cultura y religiosidad, las relaciones sociales, la salud, la vivienda y hábitat. Generadaa partir de procesos de sometimiento, imposición, explotación de grupos legales o ilegales contra personas, poblaciones o naciones y en las cuales resultan violados y vulnerados uno o varios de los derechos humanos, de los pueblos y de la naturaleza.

Es preciso entender algunas de las tensiones que están en juego cuando ocurre dicha ruptura como se ilustra a continuación:

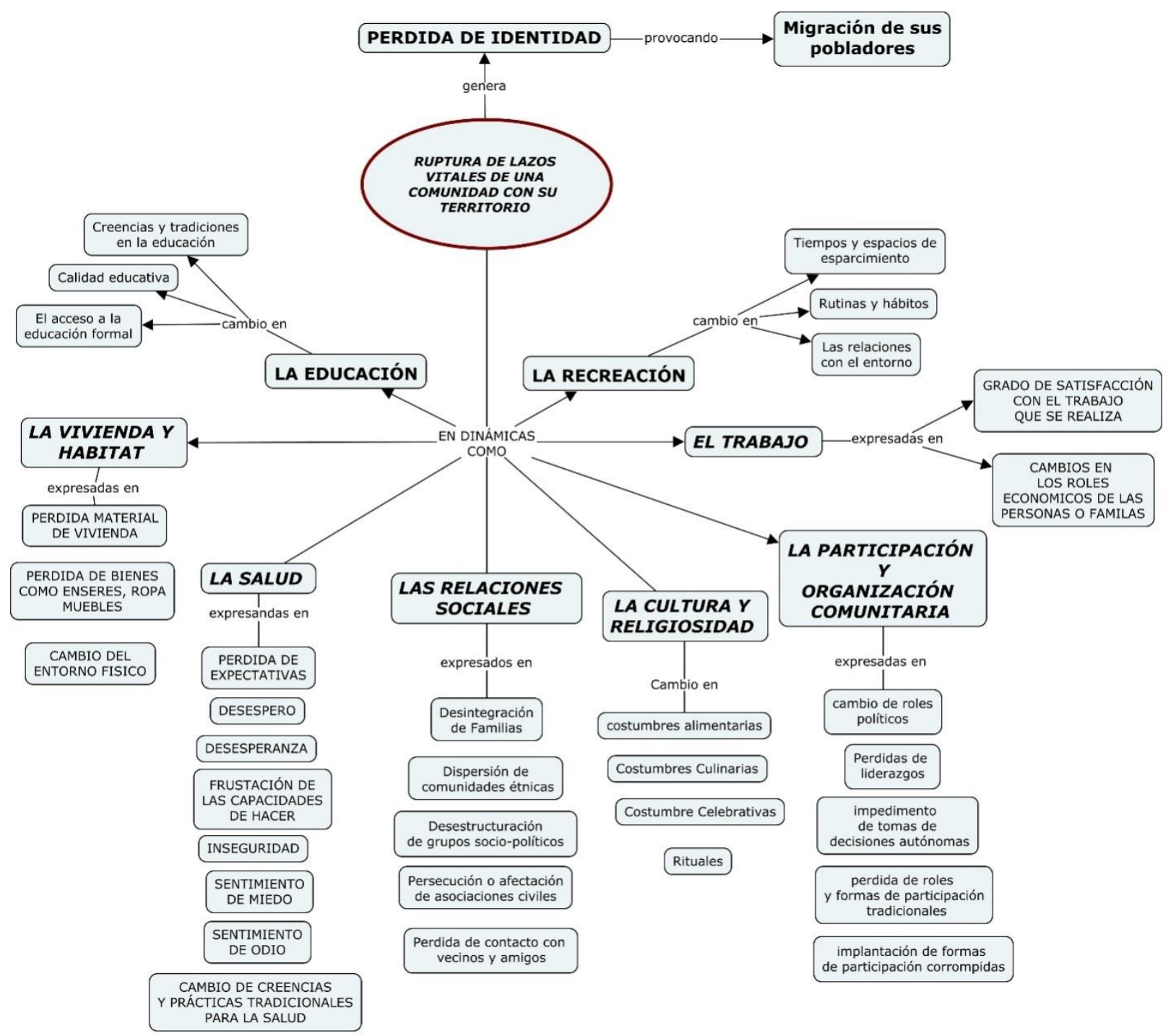

Como se observa, las categorías en mención, se consideran un lazo vital en los territorios por las siguientes razones: 
- El trabajo: Ya que, mediante esta relación, se fragua la forma de vida para la subsistencia y rol dentro de una comunidad para la convivencia; Se considera que la ruptura de este lazo vital puede verse expresado en el grado de satisfacción con el trabajo que se realiza, pues un bajo grado de satisfacción puede estar asociado a trabajos en los cuales absorbe el tiempo de estos trabajadores, pero que no pueden dejar, por ser el único medio de subsistencia de su familia, incluso en algunos casos las personas deben someterse al maltrato de sus jefes con la finalidad de mantener su cargo. En este caso,cuando el grado de insatisfacción es alto con el trabajo, incide directamente en la vida comunitaria, porque estas personas tienden estar agotadas mental y espiritualmente como para ocuparse en asuntos de comunidad y en algunos casos hasta con la familia misma. Por ello esta ruptura tiene que ver con los cambios en los roles económicos de las personas o familias, porque las actividades de un conjunto de personas en un territorio determinado dejan de estar vinculadas a la vida comunitaria, se vuelven independientes y la contribución o rol dentro de un territorio no es visible para los demás, por ende, dicha situación aísla a las personas unas de las otras.

- La participación y organización comunitaria: lazo fundamental para llegar a consensos y acuerdos que permitan la armonía y mejoramiento del espacio y lugar de convivencia; la ruptura de este lazo vital, puede verse expresadas en cambios en los roles políticos por la imposición formas corruptas de participación de agrupaciones económicas, que buscan en algunas casos intimidar y acallar situaciones de vulneración de los derechos de los pueblos y la naturaleza, Algunas de estas agrupaciones intimidan a la comunidades promoviendo al perdida de liderazgos, impidiendo que las comunidades tomen decisiones autónomas y desprestigiando los roles y formas de participación tradicionales.

- La cultura y religiosidad: lo cual está relacionado con la espiritualidad, cosmovisión y prácticas que mantienen la unión y solidaridad entre la comunidad; La ruptura de este vínculo se expresa en cambios en costumbres alimentarias, celebrativas, rituales, cosmovisión frente a la vida en algunos casos alienados por la modernidad y la propagación a nivel global del consumismo a través de estilos de vida que desprestigian las tradiciones culturales de los pueblos.

- Las relaciones sociales: es el lazo que denota comunicación, intercambio de experiencias, enseñanzas, tradiciones y disfrute del tiempo libre; La ruptura de este vínculo se podría ver expresada por la desintegración familiar, dispersión de las comunidades étnicas, la destrucción de los grupos sociopolíticos, persecución o afectación de las asociaciones civiles, perdida de contacto con vecinos y amigos. Porque estas situaciones denotan mecanismos de sometimiento que trasgreden o impiden las relaciones 
fuertes en comunidad, un ejemplo de ello es la intimidación que causa la estigmatización a las organizaciones sociales y el asesinato de líderes comunitarios.

- La salud: Lazos asociados al cuidado del cuerpo de diversas maneras; La ruptura de este vínculo pretende asociar integralmente los pensamientos, espiritualidad y como estos se reflejan en el cuerpo, por ello se considera que la ruptura de este lazo vital se ve expresado en la perdida de expectativas, el desespero, desesperanza, frustración en las capacidades de hacer, la inseguridad, sentimiento de miedo y de odio, cambio de creencias y prácticas tradicionales para la salud.

- La vivienda y hábitat: lazo asociado al lugar en el cual cada familia vive; la ruptura de este vínculo puede estar asociado a la perdida material de la vivienda, de los muebles, enseres, ropa o el simple cambio de entorno físico derivado de diferentes procesos de sometimiento como por ejemplo el conflicto armado, la violencia, el desempleo, la contaminación entre otros factores.

- La educación: Lazo de enseñanzas e instituciones importantes para el trabajo y la vida en comunidad, se considera que la ruptura de este lazo se expresa fundamentalmente, en el cambio en las creencias y tradiciones en la forma de transmisión de conocimientos, el acceso a la educación formal se convierte en el requisito para entrar en el sistema económico, así como también la necesidad de la calidad educativa. Se observa que el mecanismo de sometimiento más fuerte, es por medio de la educación que hoy en día ha adquirido una mirada unidimensional desde la ciencia y los conocimientos científicos que de alguna manera colocan en situación de atraso los saberes tradicionales.

- La recreación: lazos que aumenta relaja el espíritu, incentiva la solidaridad y acercamiento con el otro; la ruptura de este vínculo se ve expresado con el cambio en los tiempos de esparcimiento, las rutinas y hábitos que ya no se vinculan con compartir en familia, con los vecinos y el entorno que los rodean. Se considera que esta ruptura puede estar asociada a imposiciones de modelos económicos que venden el entretenimiento y disfrute del tiempo libre, en otras prácticas como ver televisión o ir a lugares costosos entre otros.

Cuando ocurre esto que se denomina ruptura, todas estas dinámicas propias de una comunidad entran en tensión, así por ejemplo si estamos hablando de una población desplazada, se encuentra que, en dinámicas como el trabajo, el estilo de vida cambia totalmente si están en la ciudad, puesto que deben adaptarse a cambios en los roles económicos muy diferentes a los habituales.

Ahora si se observa el territorio sobre el cambio que ha significado la dinámica del trabajo en la modernidad, existe un común denominador, el crecimiento 


\begin{tabular}{|l|l|}
\hline \multicolumn{2}{|c|}{ EL TRABAJO } \\
\hline & $\begin{array}{l}\text { Grado de satisfacción con el trabajo } \\
\text { que se realiza }\end{array}$ \\
\cline { 2 - 2 } Rastrear cambios en & $\begin{array}{l}\text { Roles económicos de las familias y } \\
\text { personas }\end{array}$ \\
\cline { 2 - 2 } & $\begin{array}{l}\text { Cantidad de tiempo dedicada al } \\
\text { trabajo }\end{array}$ \\
\cline { 2 - 2 } & $\begin{array}{l}\text { Vínculos entre el trabajo y la familia, la } \\
\text { comunidad y el territorio }\end{array}$ \\
\cline { 2 - 2 } & $\begin{array}{l}\text { Los conocimientos que deben } \\
\text { adquirirse para trabajar }\end{array}$ \\
\hline & Que se necesita para trabajar \\
\hline El propósito con el trabajo \\
\hline
\end{tabular}

económico, un sistema globalizado que se expande a través del discurso del progreso, desarrollo. Despoja o rompe con el lazo comunitario más importante en una comunidad el trabajo. De esta manera, se desprestigia las labores tradicionales imponiendo y desligando el trabajo de su vida en comunidad.

Por ello resulta de gran relevancia al analizar cada una de las categorías mencionadas, ya que están pueden dar vistas aproximadas de lo que realmente sucede con un territorio y que puede dar como resultados lecturas sobre lo que realmente se quiere y desea construir. Ya que, si se entiende los lazos que deben reconstruirse quizás sea posible generar nuevas territorialidades más sensatas con la humanidad y el planeta.Cada una de estas categorías se propone sean analizadas de la siguiente manera: 
En este sentido, con dicho análisis se intenta reconocer rupturas en las dinámicas del trabajo, cómo han cambiado, qué vínculos tiene con el territorio y reconocer qué tan apropiados puede estar determinada población con su territorio desde la dinámica del trabajo.

\begin{tabular}{|c|c|}
\hline \multicolumn{2}{|c|}{ RELACIONES SOCIALES } \\
\hline \multirow{7}{*}{ Rastrear cambios en } & $\begin{array}{l}\text { El grado de contacto con amigos y } \\
\text { vecinos }\end{array}$ \\
\hline & $\begin{array}{l}\text { Características de los vínculos con los } \\
\text { vecinos }\end{array}$ \\
\hline & Relaciones familiares \\
\hline & $\begin{array}{l}\text { Características de los vínculos con los } \\
\text { amigos }\end{array}$ \\
\hline & $\begin{array}{l}\text { En la participación conjunta en } \\
\text { actividades }\end{array}$ \\
\hline & $\begin{array}{l}\text { Las redes sociales para resolver } \\
\text { situaciones adversas }\end{array}$ \\
\hline & La confianza entre los vecinos \\
\hline
\end{tabular}

Se considera que entender y rastrear las relaciones sociales en un territorio es fundamental, pues este análisis da insumos para comprender las intencionalidades en juego, las conflictividades, así como también entender cuáles son las relaciones que están rotas y deben construirse para fortalecer la vida comunitaria.

\begin{tabular}{|l|l|}
\hline \multicolumn{2}{|c|}{ PARTICIPACIÓN Y ORGANIZACIÓN COMUNITARIA } \\
\hline \multirow{4}{*}{ Rastrear cambios en } & $\begin{array}{l}\text { Participación en proyectos } \\
\text { comunitarios }\end{array}$ \\
\hline & $\begin{array}{l}\text { Interés en participar en entornos } \\
\text { comunitarios }\end{array}$ \\
\hline & Significado de la vida en comunidad \\
\hline & Organización comunitaria \\
\hline & Reglas de convivencia \\
\hline & $\begin{array}{l}\text { Ética del cuidado de lo público y } \\
\text { común }\end{array}$ \\
\hline
\end{tabular}


Identificar estas características permite entender el imaginario de las personas de la vida en un territorio compartido, que incidencia tiene, que tan importante prevalece lo común sobre lo privado y como esto incide en la resolución de problemáticas comunes en los territorios.

\begin{tabular}{|l|l|}
\hline \multicolumn{2}{|c|}{ LA RELIGIOSIDAD } \\
\hline \multirow{4}{*}{ Rastrear cambios en } & Rituales religiosos \\
\cline { 2 - 2 } & $\begin{array}{l}\text { Reunión comunitaria entorno a } \\
\text { celebraciones religiosas }\end{array}$ \\
\cline { 2 - 2 } & Creencia en la divinidad \\
\cline { 2 - 2 } & Valores espirituales \\
\cline { 2 - 2 } & Importancia de la religión \\
\cline { 2 - 2 } & $\begin{array}{l}\text { Comparten creencias religiosas en el } \\
\text { entorno donde viven }\end{array}$ \\
\cline { 2 - 2 } & $\begin{array}{l}\text { Relación con el territorio y la vida en } \\
\text { comunidad }\end{array}$ \\
\hline
\end{tabular}

La religiosidad como articulador cultural por excelencia, es el lazo vital que resulta de gran importancia entender, ya que con dicho análisis se busca comprender la cosmovisión, los conflictos, la relación con el territorio, la espiritualidad humana y medida de su actuar. Desde esta categoría se dimensiona valores comunitarios, así como también permite comprender las fronteras visibles e invisibles entre las poblaciones.

\begin{tabular}{|l|l|}
\hline \multicolumn{2}{|c|}{ LA SALUD } \\
\hline & Creencias y prácticas tradicionales \\
\hline & El tratamiento a las enfermedades \\
\cline { 2 - 3 } \multirow{4}{*}{ Rastrear cambios en } & Uso de plantas medicinales \\
\hline & Atención familiar \\
\cline { 2 - 3 } & Remedios o curas \\
\cline { 2 - 3 } & Padecimiento de enfermedades \\
\hline & autocuidado \\
\cline { 2 - 2 } & Hábitos saludables \\
\cline { 2 - 2 } & $\begin{array}{l}\text { Relación con el territorio y la } \\
\text { comunidad }\end{array}$ \\
\hline
\end{tabular}

Al dimensionar esta categoría se busca comprender el grado de saberes acumulados que aún conservan las comunidades para el autocuidado y la salud, y 
de estas características comprender qué queda de estos estos saberes en la modernidad.

\begin{tabular}{|l|l|}
\hline \multicolumn{2}{|c|}{ LA VIVIENDA Y HÁBITAT } \\
\hline \multirow{4}{*}{ Rastrear cambios en } & Características de las viviendas \\
\cline { 2 - 2 } & $\begin{array}{l}\text { Espacios amplios, ventilados con } \\
\text { iluminación }\end{array}$ \\
\cline { 2 - 2 } & Propia o arriendo \\
\cline { 2 - 2 } & Espacio de reunión y regocijo \\
\cline { 2 - 2 } & Significado del hogar y el entorno \\
\hline & Vínculos con el hábitat \\
\hline & Significado familiar y colectivo \\
\hline & $\begin{array}{l}\text { Conexión vital con la vivienda y su } \\
\text { entorno }\end{array}$ \\
\hline
\end{tabular}

Esta categoría busca comprender las relaciones que se fraguan dentro de una vivienda, la vida en familia, hábitos compartidos, las relaciones que entretejen desde la vida familiar y como estas se reflejan en su entorno comunitario.

\begin{tabular}{|l|l|}
\hline \multicolumn{2}{|c|}{ LA EDUCACIÓN } \\
\hline \multirow{2}{*}{ Rastrear cambios en } & $\begin{array}{l}\text { La necesidad de acceso a educación } \\
\text { superior }\end{array}$ \\
\cline { 2 - 3 } & $\begin{array}{l}\text { Nivel educativo que se debe adquirir } \\
\text { para trabajar en una aceptable } \\
\text { remuneración }\end{array}$ \\
\cline { 2 - 2 } & $\begin{array}{l}\text { Vinculo de la educación con las } \\
\text { creencias comunitarias }\end{array}$ \\
\hline & $\begin{array}{l}\text { La importancia sobre estudiar } \\
\text { La enseñanza o transmisión de saberes } \\
\text { tradicionales }\end{array}$ \\
\hline
\end{tabular}

La educación como la dinámica comunitaria de transmisión de conocimientos, que moldea la conducta y hábitos de las personas, se busca rastrear la brecha entre las enseñanzas tradicionales y la inminente propagación de la educación formal derivada de la modernidad sobre los saberes ancestrales y comunitarios.

\begin{tabular}{|l|l|}
\hline \multicolumn{2}{|c|}{ LA RECREACIÓN } \\
\hline \multirow{4}{*}{ Rastrear cambios en } & $\begin{array}{l}\text { Tiempos y espacios para el } \\
\text { esparcimiento }\end{array}$ \\
\cline { 2 - 3 } actividades que realizan \\
\cline { 2 - 2 } & $\begin{array}{l}\text { rutinas y hábitos } \\
\text { relación establecida entre las familias y } \\
\text { el entorno }\end{array}$ \\
\hline
\end{tabular}




\begin{tabular}{|l|l|}
\hline \multirow{2}{*}{} & $\begin{array}{l}\text { Actividades que realiza en el entorno } \\
\text { donde se vive }\end{array}$ \\
& $\begin{array}{l}\text { Pago para acceder a servicios } \\
\text { recreativos }\end{array}$ \\
\hline $\begin{array}{l}\text { Gusto sobre permanecer en su entorno } \\
\text { y compartir en comunidad }\end{array}$ \\
\hline
\end{tabular}

Esta dimensión pretende identificar las actividadescomunitarias, si estas están vinculadas con el entorno y el quehacer diario o si por el contrario estas relaciones son inexistentes y si las familias prefieren el encierro. También permite identificar esos factores que inciden en esta dinámica.

Al comprender estos lazos y sus rupturas es fundamental analizar paralelamente con el fenómeno de desarraigo, los diversos intereses de apropiación del territorio y los mecanismos que se usan para el sometimiento, que mantienen rotos los lazos comunitarios e impide las formas alternativas de vida.

La siguiente ilustración muestra una serie de mecanismos de sometimiento que reprime y mantiene dominada a las poblaciones que impiden la reconstrucción de lazos comunitarios rotos.

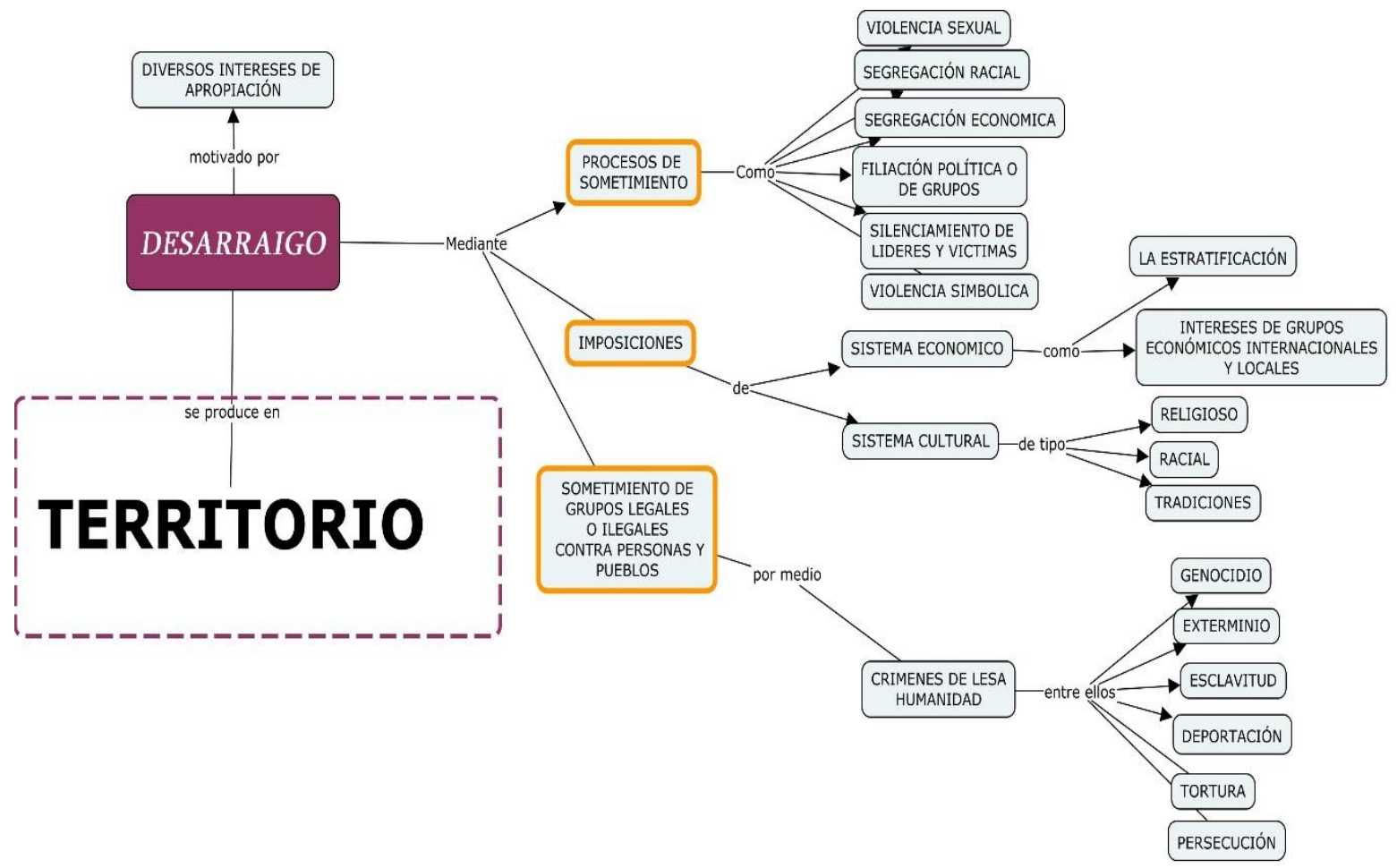


De esta manera, el desarraigo que implica rupturas en el tejido social, es un fenómeno motivado por diversos intereses de apropiación del territorio por parte de agrupaciones sociales que se sirven de diferentes mecanismos, para debilitar la cohesión social la cual resulta ser la principal amenaza para las imposiciones hegemónicas.

En este sentido, la ilustración intenta mostrar algunos de procesos de sometimiento e imposiciones más representativas que trasgreden la vida comunitaria, así como el disfrute pleno de los derechos de las personas y la naturaleza. Por ello se considera que estos factores deben ser analizados de la siguiente manera:

\begin{tabular}{|c|c|c|c|}
\hline Lazos vitales & Lectura del contexto & $\begin{array}{c}\text { Existencia del } \\
\text { lazo vital } \\
\text { comunitario }\end{array}$ & $\begin{array}{l}\text { Imposiciones } \\
\text { analizadas en el caso }\end{array}$ \\
\hline El trabajo & $\begin{array}{l}\text { Se observa y anota los } \\
\text { cambios en relación } \\
\text { con la dinámica del } \\
\text { trabajo de la población } \\
\text { en estudio, formas de } \\
\text { remuneración, } \\
\text { satisfacción con el } \\
\text { trabajo, vínculos entre } \\
\text { esta dinámica y la vida } \\
\text { en familia y } \\
\text { comunitaria entre } \\
\text { otros. Después de } \\
\text { haber dimensionado } \\
\text { cada categoría }\end{array}$ & 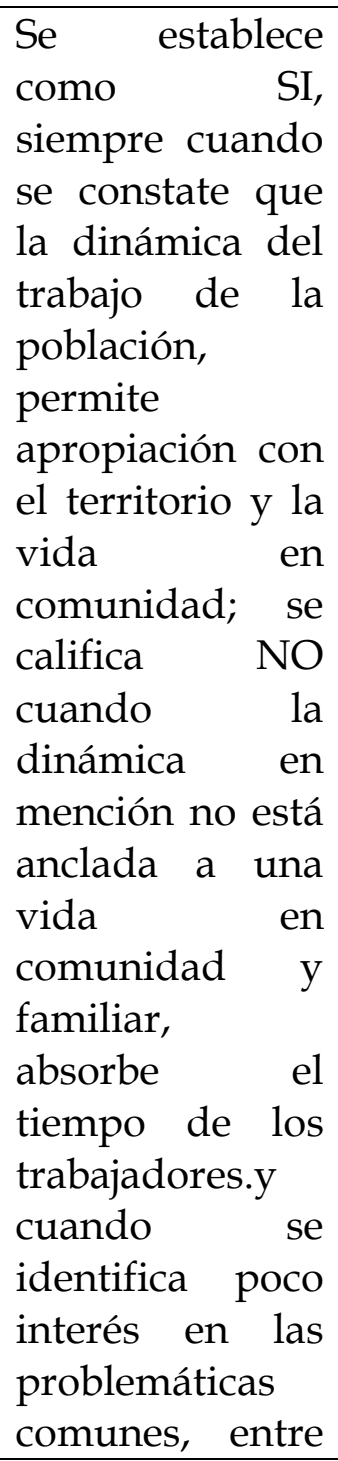 & $\begin{array}{l}\text { Cuando se establece } \\
\text { la No existencia del } \\
\text { lazo } \\
\text { comunitario, se debe } \\
\text { vincular los posibles } \\
\text { procesos } \\
\text { sometimiento que } \\
\text { impiden ra } \\
\text { reconstrucción del } \\
\text { lazo, Por ejemplo, si } \\
\text { se trata de una } \\
\text { población campesina } \\
\text { desplazada, se podría } \\
\text { analizar procesos de } \\
\text { sometimiento como: } \\
\text { la imposición de un } \\
\text { modelo económico de } \\
\text { producción, ra } \\
\text { intimidación pr por } \\
\text { parte de grupos } \\
\text { armados, legales e } \\
\text { ilegales, entre otros. }\end{array}$ \\
\hline
\end{tabular}




\begin{tabular}{|c|c|c|c|}
\hline & & otros factores. & \\
\hline $\begin{array}{c}\text { Relaciones } \\
\text { sociales }\end{array}$ & $\begin{array}{l}\text { Se observa y anota el } \\
\text { análisis del grado de } \\
\text { contacto con amigos y } \\
\text { vecinos, sus vínculos, } \\
\text { en la participación } \\
\text { conjunta } \\
\text { actividades, confianza } \\
\text { y lazos de solidaridad } \\
\text { en el territorio en } \\
\text { estudio. }\end{array}$ & \begin{tabular}{lr}
\multicolumn{3}{l}{ Se califica como } \\
SI, cuando se \\
encuentra que \\
las relaciones \\
analizadas en el \\
territorio son \\
fuertes & que \\
genera & un \\
ambiente & de \\
solidaridad & y \\
confianza; & Se \\
califica & No \\
cuando & la \\
dinámica & de \\
estas relaciones \\
son \\
indiferencia y se \\
evidencia bajos \\
grados \\
$\begin{array}{lr}\text { solidaridad } \\
\text { confianza }\end{array}$ \\
\end{tabular} & 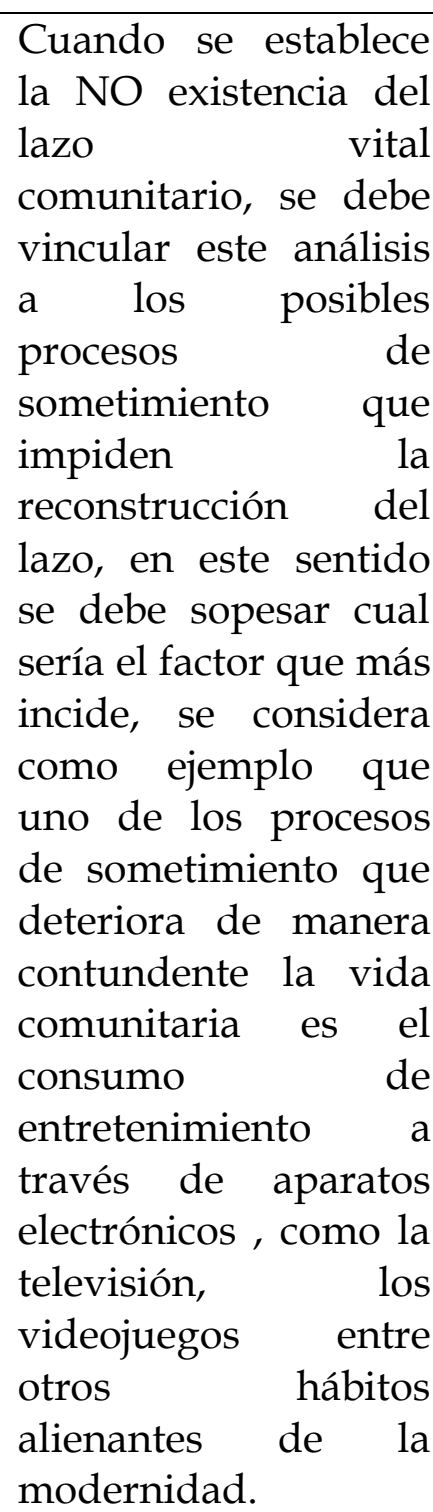 \\
\hline $\begin{array}{c}\text { La participación } \\
\text { y organización } \\
\text { comunitaria }\end{array}$ & $\begin{array}{l}\text { Se observa y anota } \\
\text { cada las características } \\
\text { de la población } \\
\text { entorno a la } \\
\text { participación, interés } \\
\text { por lo comunitario, } \\
\text { acciones comunitarias } \\
\text { en función del } \\
\text { territorio y su lugar de } \\
\text { habitabilidad }\end{array}$ & 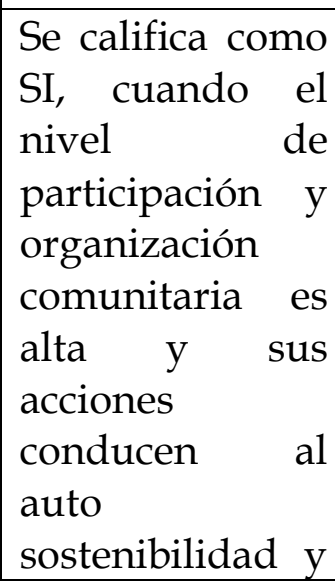 & $\begin{array}{l}\text { Cuando se establece } \\
\text { la NO existencia del } \\
\text { lazo vital } \\
\text { comunitario, se debe } \\
\text { vincular este análisis } \\
\text { a los posibles } \\
\text { procesos } \\
\text { sometimiento de } \\
\text { impiden la } \\
\text { reconstrucción del } \\
\text { lazo, como, por }\end{array}$ \\
\hline
\end{tabular}




\begin{tabular}{|c|c|c|c|}
\hline & & $\begin{array}{l}\text { en armonía con } \\
\text { la naturaleza; Se } \\
\text { califica NO } \\
\text { cuando la } \\
\text { participación es } \\
\text { baja, los vecinos } \\
\text { entre si no se } \\
\text { conocen, la } \\
\text { organización } \\
\text { comunitaria es } \\
\text { débil entre otros } \\
\text { factores }\end{array}$ & $\begin{array}{lr}\text { ejemplo, } & \text { la } \\
\text { intimidación } & \text { por } \\
\text { parte de } & \text { grupos } \\
\text { armados, } & \text { la } \\
\text { modernidad con } & \text { su } \\
\text { dinámica } & \text { de } \\
\text { indiferencia, } & \text { la } \\
\text { corrupción, } & \text { la } \\
\text { violencia simbólica. }\end{array}$ \\
\hline La religiosidad & $\begin{array}{l}\text { Se anota el análisis } \\
\text { frente a la } \\
\text { cosmovisión, creencias, } \\
\text { rituales religiosos del } \\
\text { territorio en estudio } \\
\text { identificando si dichas } \\
\text { creencias permite la } \\
\text { reunión comunitaria } \\
\text { entorno a las } \\
\text { celebraciones } \\
\text { religiosas, permitiendo } \\
\text { la cohesión social. }\end{array}$ & 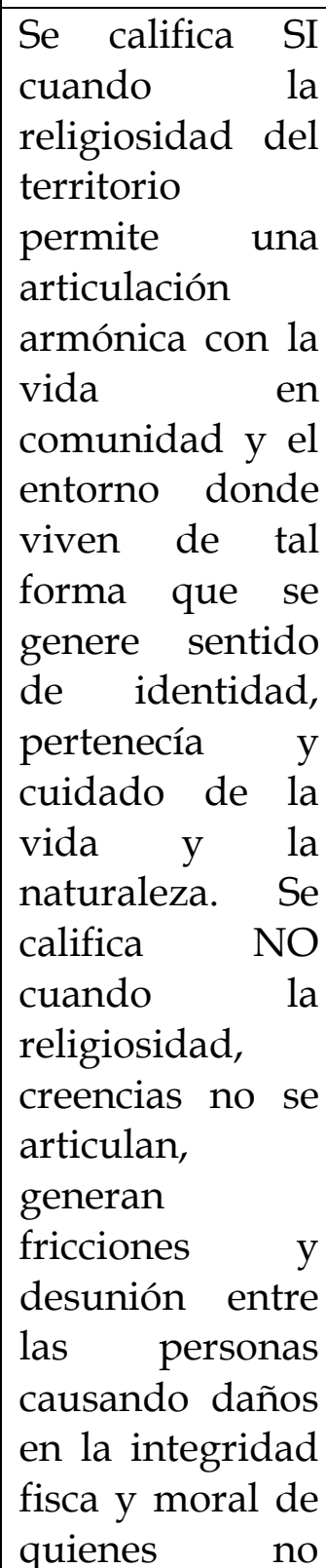 & $\begin{array}{lr}\text { Cuando se califica la } \\
\text { NO existencia del } \\
\text { lazo vital, debe } \\
\text { considerarse r el } \\
\text { mecanismo de } \\
\text { sometimiento que } \\
\text { más incide, uno de } \\
\text { ellos puede ser } \\
\text { atribuido a la } \\
\text { imposición de } \\
\text { religiones a la fuerza } \\
\text { mediante diferentes } \\
\text { métodos de exclusión } \\
\text { y vulneración del } \\
\text { libre albedrío de las } \\
\text { personas. }\end{array}$ \\
\hline
\end{tabular}




\begin{tabular}{|c|c|c|c|}
\hline & & $\begin{array}{l}\text { comparten } \\
\text { creencias } \\
\text { valores. }\end{array}$ & \\
\hline La salud & $\begin{array}{l}\text { Se anota el análisis de } \\
\text { lo que se identificó en } \\
\text { relación con las } \\
\text { creencias y prácticas } \\
\text { tradicionales, } \\
\text { tratamiento a las } \\
\text { enfermedades, uso de } \\
\text { plantas medicinales, } \\
\text { remedios curas, } \\
\text { hábitos de autocuidado } \\
\text { y salud, en función a la } \\
\text { vida comunitaria. }\end{array}$ & 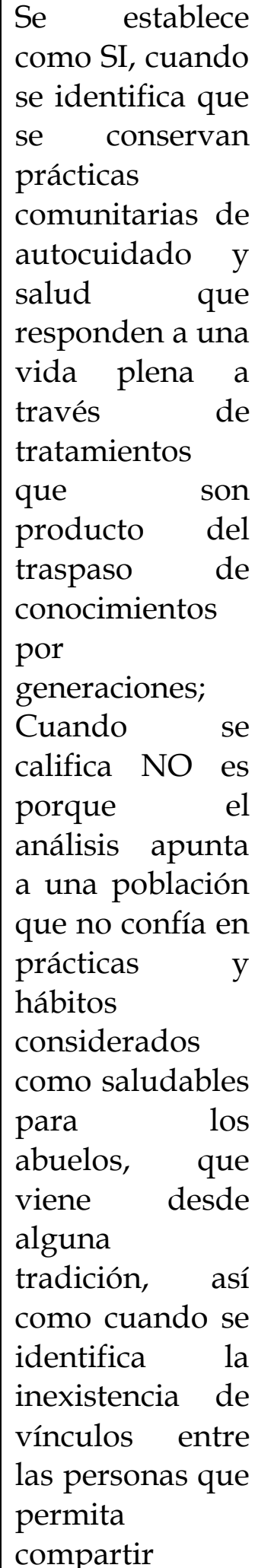 & $\begin{array}{l}\text { Cuando se califica la } \\
\text { NO existencia del } \\
\text { lazo vital se debe } \\
\text { asociar a mecanismos } \\
\text { de sometimiento } \\
\text { como por ejemplo la } \\
\text { medicina moderna, el } \\
\text { sistema de salud, } \\
\text { mecanismos } \\
\text { publicitarios, } \\
\text { empresas } \\
\text { farmacéuticas que } \\
\text { han debilitados los } \\
\text { saberes tradicionales } \\
\text { entre otros pueden ser } \\
\text { identificados en este } \\
\text { aspecto. }\end{array}$ \\
\hline
\end{tabular}




\begin{tabular}{|c|c|c|c|}
\hline & & 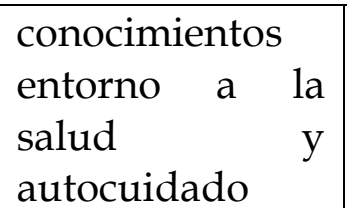 & \\
\hline $\begin{array}{c}\text { La vivienda y } \\
\text { hábitat }\end{array}$ & $\begin{array}{l}\text { Se anota el análisis de } \\
\text { las características de } \\
\text { las viviendas y sentido } \\
\text { de apropiación con su } \\
\text { entorno, los } \\
\text { significados alrededor } \\
\text { de la vivienda y el } \\
\text { espacio en común que } \\
\text { comparten con sus } \\
\text { vecinos y la familia e } \\
\text { identificar si estos } \\
\text { vínculos fortalecen o } \\
\text { deterioran la vida en } \\
\text { comunidad. }\end{array}$ & 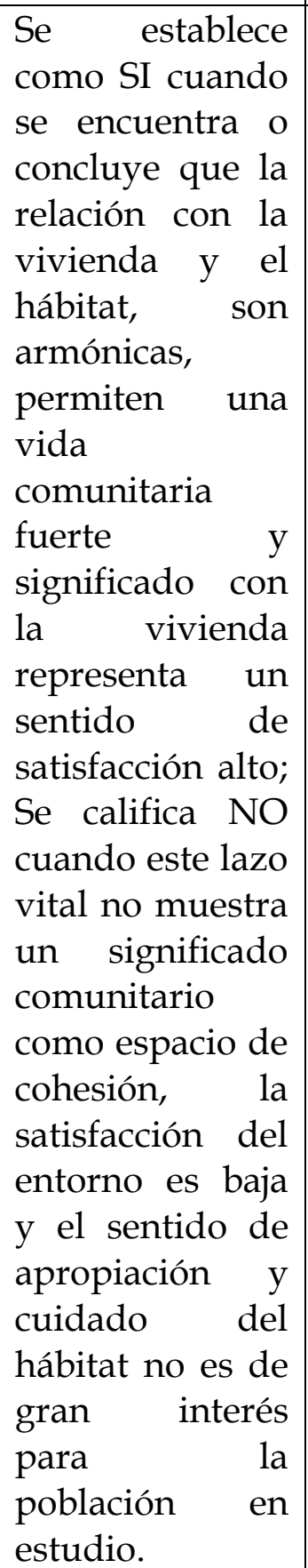 & $\begin{array}{l}\text { En este caso la } \mathrm{NO} \\
\text { existencia del lazo } \\
\text { vital pueden ser } \\
\text { asociados a múltiples } \\
\text { factores, } \\
\text { algunos de ellos } \\
\text { pueda deberse a } \\
\text { acciones ilegales, o el } \\
\text { funcionamiento de } \\
\text { empresas } \\
\text { contaminan que } \\
\text { entorno, se debe } \\
\text { tratar de sopesar cual } \\
\text { es el factor que más } \\
\text { incide para un } \\
\text { vínculo débil con la } \\
\text { vivienda y el hábitat. }\end{array}$ \\
\hline La Educación & $\begin{array}{l}\text { Se anota el análisis del } \\
\text { vínculo de la } \\
\text { educación con las } \\
\text { creencias comunitarias, } \\
\text { en este sentido se debe }\end{array}$ & $\begin{array}{ll}\text { Se establece } & \mathrm{Si} \\
\text { cuando } & \text { se } \\
\text { observa que } & \text { la } \\
\text { educación } & \text { se } \\
\text { constituye en } & \text { el } \\
\end{array}$ & $\begin{array}{l}\text { Cuando se establece } \\
\text { la No existencia del } \\
\text { lazo comunitario, se } \\
\text { debe } \\
\text { procesos }\end{array}$ \\
\hline
\end{tabular}




\begin{tabular}{|c|c|c|c|}
\hline & $\begin{array}{l}\text { observar la } \\
\text { importancia de la } \\
\text { trasmisión de saberes } \\
\text { tradicionales en las } \\
\text { generaciones jóvenes } \\
\text { así como la influencia } \\
\text { de la educación en la } \\
\text { modernidad. }\end{array}$ & $\begin{array}{l}\text { pilar de } \\
\text { cohesión } \\
\text { comunitaria y } \\
\text { que por medio } \\
\text { de esta no solo } \\
\text { se trasmiten } \\
\text { saberes sino que } \\
\text { se afianzan, se } \\
\text { investigan y } \\
\text { crecen en } \\
\text { función de la } \\
\text { vida armónica } \\
\text { en comunidad y } \\
\text { el entorno; Se } \\
\text { establece NO } \\
\text { cuando la } \\
\text { educación es un } \\
\text { elemento } \\
\text { desligado a la } \\
\text { comunidad, a la } \\
\text { familia y solo } \\
\text { sirve en función } \\
\text { del mercado y la } \\
\text { modernidad. }\end{array}$ & $\begin{array}{l}\text { sometimiento como } \\
\text { por el sistema } \\
\text { educativo dominante } \\
\text { en el cual la mayor } \\
\text { parte de la población } \\
\text { estudia determinadas } \\
\text { carreras en función } \\
\text { del sistema } \\
\text { económico, entre } \\
\text { otros factores que } \\
\text { pueden analizarse en } \\
\text { torno a la educación y } \\
\text { la perdida de saberes } \\
\text { ancestrales. }\end{array}$ \\
\hline La Recreación & $\begin{array}{l}\text { Se observa y anota el } \\
\text { análisis del vínculo } \\
\text { existente entre el } \\
\text { territorio como espacio } \\
\text { de para el } \\
\text { esparcimiento, } \\
\text { compartir actividades, } \\
\text { así como el gusto sobre } \\
\text { permanecer en el lugar } \\
\text { y compartir en } \\
\text { comunidad. }\end{array}$ & 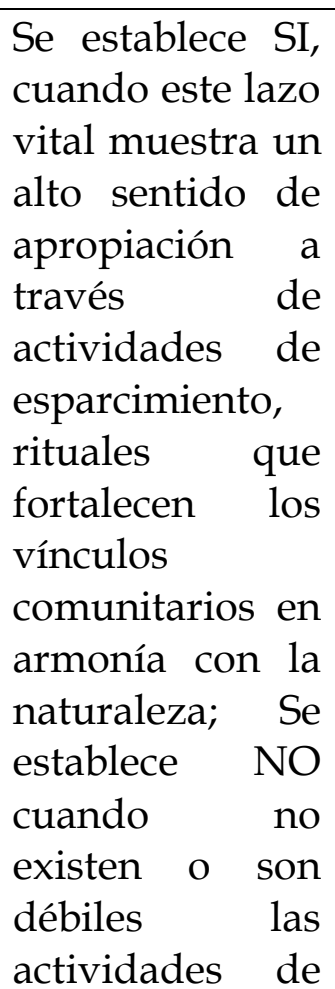 & $\begin{array}{l}\text { Cuando se establece } \\
\text { la NO existencia de } \\
\text { este lazo vital, } \\
\text { algunos de los } \\
\text { factores podrían estar } \\
\text { asociados a la falta de } \\
\text { espacios públicos } \\
\text { agradables para dicho } \\
\text { compartir, que puede } \\
\text { derivarse de un } \\
\text { sistema económico } \\
\text { que excluye ciertos } \\
\text { sectores } \\
\text { poblacionales. }\end{array}$ \\
\hline
\end{tabular}




\begin{tabular}{|c|c|c|}
\hline & & $\begin{array}{l}\text { esparcimiento } \\
\text { que propicien la } \\
\text { vida } \\
\text { comunitaria, así } \\
\text { como también } \\
\text { cuando se } \\
\text { evidencia el bajo } \\
\text { interés de la } \\
\text { comunidad de } \\
\text { compartir en } \\
\text { estosesnacios }\end{array}$ \\
\hline
\end{tabular}

Al realizar este análisis paralelo se puede comprender cómo el fenómeno de desarraigo trasgrede los derechos de los pueblos y la naturaleza

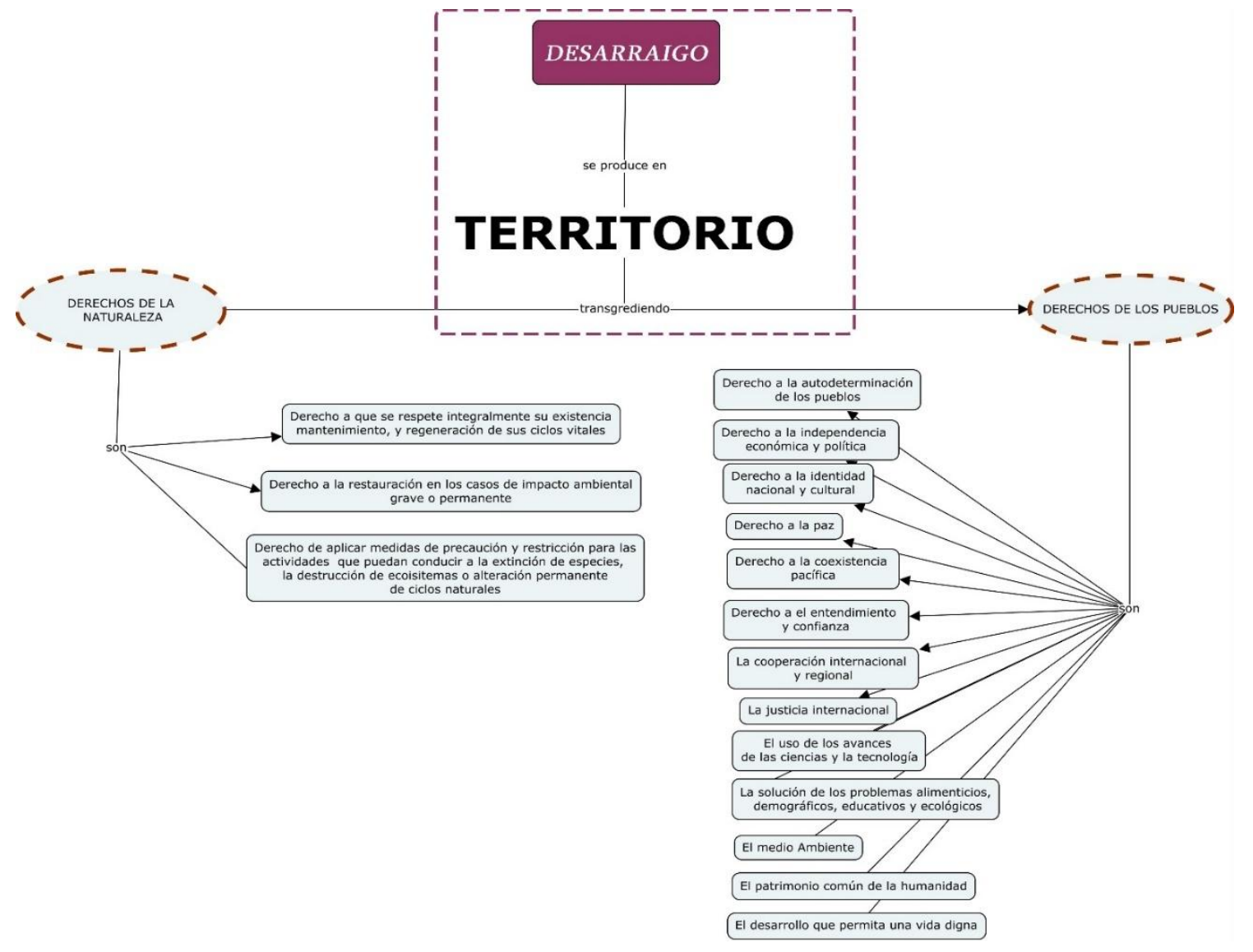

Desde un enfoque de derechos, este desarraigo transgrede directamente la declaración universal de los Derechos de los pueblos del 4 de julio de 1976 que son: 
- Derecho a la existencia: Indica que "...todo pueblo tiene derecho a conservar en paz la posesión de su territorio y de retornar allí en caso de expulsión...nadie puede ser, debido a su identidad nacional o cultural, objeto de masacre, tortura, persecución deportación, o expulsión, o ser sometido a condiciones de vida que puedan comprometer la identidad o la integridad del pueblo al que pertenece..." (Unidas N. , 2016)

- Derecho a la autodeterminación política: indica que “...Él determina su status político con toda libertad y sin ninguna injerencia exterior...todo pueblo tiene derecho a liberarse de toda dominación colonial o extranjera directa o indirecta y de todos los regímenes racistas..." (Unidas N. , 2016)

- Derechos económicos de los pueblos: indica que "...todo pueblo tiene un derecho exclusivo sobre sus riquezas y sus recursos naturales. Tiene derecho a recuperarlos si ha sido expoliado, y a cobrar las indemnizaciones injustamente pagadas...todo pueblo tiene derecho a que su trabajo sea justamente evaluado, y a que los intercambios se hagan en condiciones de igualdad y equidad...todo pueblo tiene derecho de darse el sistema económico y social que elija y de buscar su propia vía de desarrollo económico, con toda libertad y sin injerencia exterior..."(Unidas N. , 2016)

- Derecho a la cultura: indica que "...todo pueblo tiene derecho hablar su propia lengua, de preservar y desarrollar su propia cultura, contribuyendo así a enriquecer la cultura de la humanidad...tiene derecho a sus riquezas artísticas, históricas y culturales...a que no se le imponga una cultura extranjera..." (Unidas N. , 2016)

- Derecho al medio ambiente y los recursos naturales: indica que “...todo pueblo tiene derecho a la conservación, la protección y el mejoramiento de su medio ambiente...a utilizar el patrimonio común de la humanidad, tal como la alta mar, el fondo de los mares, el espacio extraatmosférico...coordinar las exigencias de su desarrollo económico con las de la solidaridad entre todos los pueblos del mundo"(Unidas N. , 2016)

- Derechos de las minorías: indica que “...Cuando en el seno de un Estado, un pueblo es una minoría, tiene derecho a que se respeten su identidad, sus tradiciones, su lengua y su patrimonio cultural"(Unidas N. , 2016)

En cuanto los derechos de la naturaleza, que han sido reivindicados en la constitución política de Ecuador(2008)es ejemplo de la ruptura con la modernidad, puesto que la naturaleza pasa de ser objeto a sujeto de derechos, que cuenta con valores intrínsecos reconociendo una necesidad de justicia ecológica. (Gudynas, 2010)

Se reconocen entonces valores intrínsecos considerando que “...en un mundo sin personas, las plantas y animales continuarán con su marcha evolutiva y estarán 
inmersos en sus contextos ecológicos, y esa manifestación de la vida es un valor en sí mismo. Esta perspectiva es denominada biocéntrismo, en atención a su énfasis en valorar todas las formas de vida, tanto humanas como no-humanas"(Gudynas, 2010, pág. 50)

Se reivindica a la naturaleza desde una perspectiva ecológica donde otro tipo de valores como el estético, religioso, cultural resultan ser más relevante que la tradicional visión antropocéntrica en la cual la naturaleza es vista como un recurso que provee al ser humano y la economía.

La apuesta entonces, de análisis del territorio desde lo que ha significado el fenómeno del desarraigo, incluye que más allá de esta ruptura de lazos vitales, esta ruptura debe ser observada a la luz de los procesos de sometimiento identificados, así como los derechos de los pueblos y la naturaleza transgredidos.

Si se logra entender en un territorio la dimensión de sus rupturas de acuerdo con los caracteres expuestos, sería posible dimensionar cuáles son los vínculos más importantes para restablecerse y de esta manera crear iniciativas que permitan la construcción de nuevos proyectos de vida en base a sus experiencias.

Así, por ejemplo, el fenómeno de desplazamiento ha tomado mayor relevancia en el siglo XXI debido a la crisis humanitaria que ha venido representado este flujo migratorio de personas en todo el mundo y generalmente asociado a la constante violación de los derechos que la humanidad históricamente ha venido promulgando por medio de tratados, convenciones, leyes entre otros para prevenir su vulneración y proteger en general al ser humano.

Sin embargo, según la Agencia de la ONU para los refugiados ACNUR en el año 2016 indica que el desplazamiento forzado en todo el mundo supera los 60 millones de personas "Cada vez hay más gente desplazada por la guerra y la persecución y esto ya es preocupante, pero los factores que ponen en peligro a los refugiados también se están multiplicando", dijo el Alto Comisionado de la ONU para los Refugiados, Filippo Grandi." (ACNUR, 2016). Resulta ser una cifra alarmante que da muestra de la incapacidad de los gobiernos de resolver conflictos, proteger a los más vulnerables y sobre todo garantizar el goce efectivo de los derechos.

Hasta el momento, existe amplias discusiones en torno al problema de desplazamiento y conflicto armado, que han sido documentadas en gran variedad de literatura, sin embargo, dicho concepto tiene sus limitaciones ya que según (Lozano, 2012) no muestra las rupturas que no tienen que ver con el lugar o cambiar de lugar, sino con lo que significa, son rupturas casi incalculables con sus territorios de carácter afectivo, social, moral, cultural, ambiental entre otros. 
Más allá de la movilización de un grupo de personas y la necesidad de atención de esta población existe una temática compleja por analizar y es el desarraigo que como lo menciona el Juez de la Corte Internacional de Justicia Antônio Augusto CançadoTrindade implica tener en cuenta los traumas que acarrean por ejemplo la separación y desagregación familiar, perdida de bienes materiales, el sufrimiento del abandono del hogar y el sentimiento de injusticia. (Cançado, 2016).

Para concluir este capítulo vale la pena comprender el desarraigo como uno de los puntos estructurales a la hora de hablar de crisis civilizatoria en el siglo XXI, ya que estamos asistiendo en nuestros territorios la necesidad de crear iniciativas que lleven a entender la realidad de manera diferente y a materializar acciones que permitan dar nuevas esperanzas a las poblaciones marginadas y empobrecidas.

Se requiere asumir perspectivas alternativas a la de los discursos de modernidad y desarrollo, es vital asumir desde instituciones públicas y también privadasformas de intervención alternativas y desligadas de estas corrientes dominantes,que han puesto en jaque el planeta, es decir se requiere de manera urgente de una nueva ética que despierte la sensibilidad hacia lo que está sucediendo, con la naturaleza, los animales y los seres humanos socialmente excluidos por otros de la misma especie.

“...Estamos en presencia de la crisis terminal de un patrón civilizatorio antropocéntrico, monocultural y patriarcal, de crecimiento sin fin y de guerra sistemática contra las condiciones que hacen posible la vida en el planeta tierra..."(Lander, 2012)

\section{¿Territorios de "SumakKawsay" como alternativa al desarrollo?}

Como se ha venido argumentando, actualmente nos encontramos con una gran cantidad de comunidades desarraigadas, empobrecidas y excluidas socialmente, que no necesariamente está relacionado a la falta de "desarrollo" sino a la ausencia de identidad y empoderamiento con el territorio, producto de la ruptura de los tejidos comunitarios.

En este sentido, lo que se quiere plantear es la necesidad de propiciar la reconstrucción de vínculos que generen iniciativas innovadoras, que respondan a la actual dinámica de vida planetaria en respeto a su entorno y diversidad en el amplio sentido de la palabra. A mi modo de ver, es imperante hoy en día, que los gobiernos y planificadores sociales, se planteen desde un enfoque territorial incorporar, la perspectiva del "Buen Vivir" como fin último de las personas y como alternativa a la crisis de pobreza, exclusión y vulneración de los derechos 
que han generado los sistemas hegemónicos que giran en torno a la acumulación de capital.

La perspectiva del Buen Vivir- Vivir bien que en lenguaje Kichwa se denomina "SumakKawsay", tiene su origen en las culturas ancestrales indígenas de Latinoamérica, especialmente en los países del Ecuador y Bolivia. Esta tendencia que ha venido resonando desde estos territorios, no es menos, sino el gran eco que han logrado generar estas dinámicas de resistencia a los modelos hegemónicos, los cuales exigen el respeto por la conservación de la cultura comunitaria que buscare significar y valorar los saberes ancestrales en armonía con la naturaleza.

Por ello “...se planteó el buen vivir o SumakKawsay (En Kichwa) como una oportunidad para construir otra sociedad sustentada en una convivencia ciudadana en diversidad y armonía con la naturaleza, a partir del reconocimiento de los diversos valores culturales existentes en el país y en el mundo..."(Acosta, 2012, pág. 35)

El Buen Vivir entonces, apunta a reconocer los derechos de la naturaleza, de la "pacha-mama", es decir esta vista como sujeto y no como mercancía a disposición del hombre desde la visión occidental. A promover la afirmación de la unidad entre lo humano y la naturaleza desde de los saberes y conocimientos de cualquier cultura, a visibilizar otros lugares de la democracia, a la afirmación de lo local y lo territorial en un mundo globalizado, a nuevas formas de institucionalidad, etc.

“...El reconocimiento de la diversidad significa el encuentro con un tipo de subjetividad, que produce un cuestionamiento al Estado-nación y su manera de entender los derechos...plantearse que existen otras maneras de construcción de Estado y Sociedad..."(Mejía, 2013, pág. 16).

Es decir, cada una de las acciones de un sujeto en la comunidad se convierten en acciones en el escenario político, porque el Buen vivir debe ser un proyecto centrado en los territorios, en la comunidad, en la generación de autonomía basados en el principio de la complementariedad. Una comunidad soberana y autosuficiente que enfrente el individualismo, la deshumanización y el interés privado por la ganancia.

Volviendo a las reflexiones del profesor Renán Vega, menciona un movimiento surgido por los artesanos ingleses del siglo XIX lo cuales protestaron por la forma como las máquinas y la industria naciente en esa época los expropiaba de sus saberes y labores pues “...Los lúditas defendían su modo de vida, su autonomía e independencia, todo lo cual estaba siendo arrasada por la imposición del "progreso técnico". Esto no quería decir que los lúditas habitasen en el paraíso, pero si en una sociedad que les posibilitaba mantener sus tradiciones, costumbres 
y formas de producción y trabajo, que les permitía vivir relativamente bien, pero el cambio forzoso a que los conducía el capitalismo destruía sus formas ancestrales de existencia y los arrastraba una vida indigna y miserable. Era el paso de la seguridad de su propio modo de vida, a la inseguridad absoluta del trabajo asalariado en el cual ni siquiera la supervivencia física de ellos y sus familias estaba garantizada..."(Vega Cantor, 2012, pág. 352)

Si trasladamos esta reflexión a nuestra época y entendiendo lo que ha significado el desarraigo en los diferentes territorios del planeta, se pude observar que el funcionamiento actual del sistema, requiere de un movimiento de lúditas del siglo XXI que reivindique las tradiciones, costumbres y formas de producción y trabajo tradicionales"...Por todo ello, un proceso revolucionario en el mundo de hoy debe recuperar otra visión del tiempo, en el que se reivindique, la lentitud, la quietud, el goce por disfrutar cosas fundamentales de la vida que necesitan de tiempo..."(Vega Cantor, 2012, pág. 188).

Se requiere trabajar en las comunidades para que estas rompan con las estructuras dominantes, para ello los planificadores del desarrollo deben asumir un papel de acompañamiento de las acciones que vallan más allá de la división social de la vida misma que se vive actualmente en nuestras sociedades.

“... (Citó a André Gorz) Un lugar para trabajar, otro para habitar, un tercero para aprovisionarse, un cuarto para instruirse, un quinto para divertirse. La organización del espacio continúa la desintegración del hombre iniciada con la división del trabajo en la fábrica. Para que nunca se te ocurra que trabajo, cultura, placer y vida personal pueden y deben ser una sola y misma cosa: la unidad de una vida, sostenida por el tejido social de la comunidad..."(Vega Cantor, 2012, pág. 255)

Esta idea del Buen Vivir- Vivir Bien "Sumakkawsay" rompe con el discurso mentiroso que nos habla del "bien-estar" a través del consumo, el aumento de la capacidad adquisitiva, de entrar en competencia y acumular riquezas. Pues estas dinámicas solo han producido a nivel mundial muchos más males, como son el empobrecimiento de la mayor parte de la humanidad, la desintegración de las relaciones humanas, la destrucción de la naturaleza y la frustración de todos con el vaciamiento del sentido de la vida.(Mejía, 2013)

La crisis civilizatoria nos lleva a que se mire de manera urgente la necesidad de salvaguardar la naturaleza como patrimonio de la unidad del mundo, porque estos "...modelos de desarrollo hacen parte o por lo menos son compatibles con la llamada "civilización del progreso". Así trataron de convencernos que el progreso es indefinido, por lo tanto, se asegura un futuro mejor, meta que alcanzaremos si sostenemos un incremento constante de la producción y circulación de bienes, para lo cual hay que acentuar el carácter productivo y consumidor del ser humano por 
sobre otras dimensiones de su existencia..." (Ibañez \& Aguirre Ledezma, 2013, pág. 50)

Se trata entonces, de recuperar los valores de la comunidad en el seno de la modernidad, que logre dar un giro a la concepción misma de la vida en miras de transformar las mentes alienadas por la visión de la "modernidad", en el que se considera al hombre como dueño y señor de todo, a un ser humano cuidante, jardinero o guardián de la armonía cósmica con la naturaleza. Es imprescindible hoy en día las preguntas ¿Qué pasa con los seres humanos en el territorio? y ¿cómo se da la restauración del tejido social?

Indudablemente puedo advertir que existe una variada gama de respuestas a las preguntas anteriormente formuladas, que me lleva presentar solo de manera muy somera,pero con el ánimo de generar inquietud en este punto y es sobre el papel de las artes y la cultura como dispositivos que generan profundas interacciones entre la vida comunitaria y como a través de estas es posible la transformación de la concepción de vida que le apunta el "SumakKawsay".

A mi modo de ver, una de las múltiples y diversas maneras que pueden considerarse para materializar desde la planificación una perspectiva alternativa al desarrollo como lo ha sido la del Buen Vivir, es pensarse el territorio desde la cultura comunitaria, más que desde el punto de vista deciudadanos, en donde se promueva la ampliación de capacidades, que logren generar procesos de autogestión y auto-sostenibilidad a partir de la dinamización de sus saberes y prácticas que consolide fuertes redes de apoyo y solidaridad.

Para ello, será necesario que se apueste a movilizar la creatividad y la imaginación a través de la caja de herramientas que ofrece el arte y la cultura, para la deconstrucción del tejido social, con proyectos que apunten a generar espacios culturales de apropiación y avivamiento de la diversidad cultural, así como también a la generación y más que eso, al fortalecimiento de los liderazgos comunitarios existentes e incentivar la corresponsabilidad con el planeta que nos haga consientes de la crisis que ha generado el mismo ser humano.

En concreto, el “Buen Vivir requerirá que las personas, comunidades, pueblos y nacionalidades gocen efectivamente de sus derechos, y ejerzan responsabilidades en el marco de la interculturalidad, del respeto a sus diversidades, y de la convivencia armónica con la Naturaleza" (art. 275 Constitución de Montecristi en Ecuador)

Implica salir de la visión antropocéntrica para adentrarnos en una biocéntrica, cuyo éxito dependerá de la capacidad de pensar, de proponer, de actuar, en fin, de indignarnos incluso globalmente(Ibañez \& Aguirre Ledezma, 2013). "sea por la vía 
de los derechos de la naturaleza, como el mandato por el Buen vivir, queda claro que es necesario explorar transiciones post- extractivistas"(Gudynas, 2011, pág. 278)

Indignarnos del conjunto de políticas, instrumentos e indicadores que han sido aplicados en América Latina para salir del "subdesarrollo" y llegar a la deseada condición del "desarrollo, pues resulta pertinente cuestionar la idea misma de "progreso", el sistema mundial vigente es mal desarrollador, tenemos que concluir que esto nos conduce a un mal vivir. Por lo tanto, la búsqueda de una nueva vida debe basarse en un proceso muy distinto del desarrollo tantas veces promocionado y anhelado. (Gudynas \& Acosta, 2011)

“...el Buen Vivir apunta a relaciones dinámicas y constructivas entre el mercado, la sociedad y el Estado. Se busca construir una sociedad con diversidad de distintos tipos de mercados, para no tener una sociedad de mercado, es decir, mercantilizada. No se quiere una economía controlada por monopolistas y especuladores, ni se promueve una visión estatista a ultranza de la economía..."(Gudynas \& Acosta, 2011, pág. 108)

En términos generales, este texto buscó continuar un debate y sobre todo una apuesta que está aún en proceso de construcción como lo es la perspectiva del "Buen Vivir", en donde se puso en punto crítico el concepto de "desarrollo" como uno de los dispositivos discursivos de la modernidad para el mantenimiento de los modelos hegemónicos.

Por lo tanto, se puede inferir, que el fenómeno de desarraigo es un aspecto que debe analizarse en los territorios contemporáneos, porque la ruptura con los lazos vitales que permiten la vida en comunitaria, se ha propagado de manera alarmante en el mundo, si se observa cifras de desplazamiento interno y externo alrededor del planeta, así como conflictos armados internos y externos.

Dimensionar el desarraigo, pretende observar el territorio desde una dinámica de interculturalidad y derecho a no querer entrar en dinámicas hegemónicas para superar estados de marginalidad, se considera oportuno rescatar valores intrínsecos comunitarios. Por ello, resulta pertinente dimensionar este fenómeno, tomando conciencia de los aparatos de dominación, para entender que se requiere fortalecer vínculos con el territorio y la comunidad, para hacer frente a los múltiples procesos de sometimiento.

La apuesta del "Buen Vivir", se considera entonces una de las alternativas al "desarrollo "que podrían tenerse en cuenta al momento de pensarse el territorio, 
que plantea un cambio contundente frente a las relaciones entre las personas, la naturaleza, la economía, armonía y felicidad.

Por ello, este texto se unea la tendencia de indignación global con el propósito de contribuir o al menos sembrar cierta necesidad de pensarse más allá la vida misma, que rescate las tradiciones, se restablezcan valores éticos que permitan una armoniosa relación con la naturaleza.

\section{Referencias bibliográficas}

ACNUR. (21 de junio de 2016). La Agencia de la ONU para los refugiados. Obtenido de http://www.acnur.org/t3/noticias/noticia/el-desplazamiento-forzado-en-el-mundo-batesu-cifra-record/

Acosta, A. (2012). De las alternativas del desarrollo a las alternativas al desarrollo. En A. Guillen García, \& M. (. Phélan Casanova, Construyendo el Buen Vivir (págs. 33-36). Ecuador: Pydlos.

Acosta, A., Lander, E., Eduardo, G., Wray, N., Quintero, R., Magadalena, L., . . francois, H. (2009). El Buen Vivir: Una vía para el desarrollo. Quito: Ediciones Abya-Yala.

Agudelo, Carlos Efrén. (2001). El Pacífico colombiano: de "remanso de paz" a escenario estratégico del conflicto armado Las transformaciones de la región y algunas respuestas de sus poblaciones frente a la violencia. Cuadernos de Desarrollo Rural, 7-37. Recuperado el 12 de Junio de 2016, de http://www.academia.edu/12769815/El_Pac\%C3\%ADfico_colombiano_de_remanso_de_ paz_a_escenario_estrat\%C3\%A9gico_del_conflicto_armado

Aprill, A., Holliday, E., Jeffers, F., Miyamoto, N., Abby, S., Spatz, D., . . Hayes, S. (2006). ¿Puede el arte cambiar el mundo? El poder transformador del arte para fomentar y mantener el cambio social: Una investigación cooperativa de lidership for a changing world . New York: Research Center for Leadership in Action.

Bejarano, J. A. (2010). ¿Qué es el neoliberalismo? Su significado en la historia de las ideas y en la economía. Recuperado el Junio de 2015, de http://eumed.net/cursecon/textos/bejliberalismo.htm

Blinder, A. S. (1979). Economic Policy and the Great Stagflation. New York: Academic Press.

Cançado, T. A. (20 de Junio de 2016). El desarraigo como problema humanitario y de derechos humanos frente a la conciencia jurídica universal. Obtenido de https://www.icrc.org/spa/assets/files/other/03_cancado.pdf

Carrizosa Umaña, J. (2001). Desarrollo y medio ambiente. En J. y. Sánchez, La Roca y las Mareas: ensayos sobre economía y ecología. Bogotá D.C.: IDEA UN.

Castells, D. (2007). ¿Creciendo para quién? El modelo neoliberal de crecimiento económico antipobres. Observatorio de la Economía Latinoamerica. $N$. 77. Obtenido de http://www.eumed.net/cursecon/ecolat/co/ 
Centro Nacional de Memoria Histórica. (2015). Una nación desplazada: Informe nacional del desplazamiento forzado en Colombia. Bogotá: CNMH-UARIV.

Constitución de la República del Ecuador. (2008). Decreto Legislativo \# 0 . Ecuador.

Contreras Plata, I. (2004). Breve historia del siglo XX: Un siglo de revoluciones, contrarevoluciones y guerras (frias y calientes). México D.F.: Casa Juan Pablos.

Deniz, O. (26 de Diciembre de 2012). El desarrollo la invención neoliberal. Obtenido de economiaennube.blogspot.com.co/: http://economiaennube.blogspot.com.co/2012/12/el-desarrollo-la-invencionneoliberal.html

Escobar, A. (1989). Desarrollismo, Ecologismo y nuevos movimientos sociales en America Latina. Revista Universidad de Antioquia, 58(218), 12-22.

Escobar, A. (1995). La invención del tercer mundo Construcción y deconstrucción del desarrollo. Bogotá D.C.: Grupo Editorial Norma (Edición de 2007).

Escobar, A. (2014). Sentipensar con la tierra Nuevas lecturas sobre desarrollo, terriorio y diferencia. Medellín, Colombia: Ediciones UNAULA.

Española, R. A. (27 de 03 de 2016). Universojus.com. Obtenido de http://universojus.com/diccionario/definir_rae.php?consultar=desarraigo

Estrada López, E. (Junio de 22 de 2016). Derechos de Tercera Generación. Obtenido de http://faviofarinella.weebly.com/uploads/8/7/8/2/878244/unidad_1_generaciones_de_d erechos_estrada_lopez.pdf

Foucault, M. (1977). Historia de la sexualidad-1: la voluntad de saber .México: Siglo Veintuno Editores.

Foucault, M. (1991). Politics and the Study of Discourse. En G. en Burchell, \& C. (. Gordon, The Foucault Effect studies in governamentality. Chicago: The University of Chicago Press.

Furtado, C. (1971). El poder económico: Estados Unidos y América Latina.Centro editor de América Latina.

Galeano, E. (1997). To be like them. En M. B. Rahnema, The Post-development Reader.(págs. 214 223 ). New York: Zed Books.

Gudynas, E. (2010). La senda biocéntrica: valores intrínsecos, derechos de la naturaleza y justicia ecológica. Tabula Rasa N¹3, 47-71.

Gudynas, E. (2011). Los derechos de la naturaleza en serio. En A. Acosta, \& M. E. (compiladores), La Naturaleza con derechos. De la filosofía a la política. Quito: Abya Yala.

Gudynas, E., \& Acosta, A. (2011). El buen vivir o la disolución de la idea del progreso. LA MEDICIÓN DEL PROGRESO Y DEL BIENESTAR . PROPUESTAS DESDE AMÉRICA LATINA, 103-110. 
Hilda. (26 de Noviembre de 2008). la guia. Recuperado el 22 de Junio de 2016, de derechos de tercera generación: http://derecho.laguia2000.com/parte-general/derechos-de-tercerageneracion

Ibañez, A., \& Aguirre Ledezma, N. (2013). Buen vivir, Vivir bien: Una utopía en proceso de construcción. Bogotá: Ediciones desde abajo.

Jimenez Masullo, J. (2010). EL DESARROLLO COMO DISCURSO Y EL CRECIMIENTO COMO MITO Repensando el desarrollo, explorando el postdesarrollo. TRABAJO DE GRADO PARA OPTAR POR EL TÍTULO DE SOCIÓLOGO. Bogotá D.C., Colombia: PONTIFICIA UNIVERSIDAD JAVERIANA FACULTAD DE CIENCIAS SOCIALES DEPARTAMENTO DE SOCIOLOGÍA.

Kowii, A. (s.f.). El Sumak Kawsay. Recuperado el 27 de Junio de 2016, de http://www.un.org/esa/socdev/unpfii/documents/El\%20Sumak\%20KawsayArirumaKowii.pdf

Lander, E. (Enero de 2012). ¿Un nuevo periodo histórico? crisis civilizatoria, límites del planeta, desigualdad,asaltos a la democracia, estado de guerra permanente y pueblos de resistencia. Ponencia presentada en el foro Social de Porto Alegre.

Latouche, S. (1993). In the wake of the Affluent Society, An exploration of postdevelopment.London: Zed Books.

López, F. d. (2009). CRACK DE 1929: Causas, desarrollo y consecuencias. Revista Internacional del Mundo Económico y del Derecho Volumen I, 1-16.

Lozano V., F. A. (2009). Dominios territoriales, desarraigos e imaginarios religiosos en Colombia. Una aproximación histórica. En C. G. Trabajo, América Latina y el Caribe: territorios religiosos y desafíos para el diálogo (págs. 293-317). Buenos Aires: CLACSO. Obtenido de "http://biblioteca.clacso.edu.ar/clacso/gt/20150116033848/Lozano.pdf"

Lozano, F. (2012). Prólogo. En Lozano, \& F. (Editores), Las configuraciones de los Territorios Rurales en el Siglo XXI (págs. 23-34). Bogotá:: Editorial Pontificia Universidad Javeriana.

Mançano, B. (2012). Territorio, Teoría y Política (2009). En E. L. (Editores), Las configuraciones de los Territorios Rurales en el Siglo XXI (págs. 35-62). Bogotá: Editorial Pontificia Universidad Javeriana.

Max-Neef, M., Elizalde, A., \& Martín, H. (1986). Desarrollo a escala humana opciones para el futuro. Santiago de Chile: Esta edición: Madrid, marzo de 2010. Biblioteca CF+S http://habitat.aq.upm.es. Recuperado el 11 de Enero de 2016, de http://habitat.aq.upm.es/deh/ Licencia Creative Commons 3.0 España (cc by-nc-sa)

Mejía, M. R. (2013). Presentación. En A. Ibañez, \& N. Aguirre Ledezma, Buen vivir, Vivir bien: Una utopía en proceso de construcción (págs. 3-19). Bogotá: Ediciones desde abajo.

Morande, P. (1987). Cultura y modernización en América Latina. México D.F.: Encuentro Ediciones. 
Pradenas Fierro, R. (15 de Marzo de 2008). El sistema económico neoliberal. Recuperado el 28 de Junio de 2016, de Hernanmontecinos.com: https://hernanmontecinos.com/2008/03/15/el-sistema-economico-neoliberal/

Prebisch, R. (1951). Problemas teoricos y prácticos del crecimeinto económico. México D.F.: Naciones Unidas.

Red para la construcción de territorios Sumak Kawsay y Red SIISDHES. (2016). Desplazamiento crece a pesar de tregua unilateral y des-escalamiento del conflicto. Informe de Desplazamiento 2015. Bogotá D.C.: CODHES.

REGISTRO ÚNICO DE VÍCTIMAS (RUV). (2017). Reporte general de desplazamiento en Colombia. Bogotá D.C.: Unidad Para las Víctimas. Obtenido de http://rni.unidadvictimas.gov.co/RUV

República, S. C. (2015). Teoría de la dependencia. Obtenido de http://www.banrepcultural.org/blaavirtual/ayudadetareas/politica/teoria_de_la_depende ncia

Reyes Konings, L. S. (2010). La Conferencia de Bretton Woods. Estados Unidos y el dólar como Centro de la Economía Mundial. Procesos Históricos, 72-81. Obtenido de Disponible en: http://www.redalyc.org/articulo.oa?id=20016326007

Rodrígez Diaz, S. (2012). Consumismo y sociedad: Una visión crítica del Homo Consumens. Nomadas. Revista crítica de ciencias sociales y jurídicas. Recuperado el 10 de Enero de 2017, de http://www.redalyc.org/articulo.oa?id=18126057019

Rostow, W. W. (1960). The Stages of Economic Growth: A non-Comunist Manifesto.Cambridge: Cambridge University Press.

santos, D., Vasconi, Kaplan, \& Jaguaribe. (1969). La crisis del desarrollismo y la nueva dependencia. Buenos Aires: Amorrortu editores.

Sen, A. (1999). Desarrollo y Libertad. (E. Rabasco, \& L. Toharia, Trads.) Buenos Aires: Editorial Planeta.

Unidas, C. d.-N. (21 de Junio de 2016). Comité Internacional de la cruz roja. Obtenido de https://www.icrc.org/spa/resources/documents/misc/5tdmhb.htm

Unidas, N. (28 de Marzo de 2016). Declaración universal de los derechos de los pueblos. Obtenido de http://www.filosofia.org/cod/c1976pue.htm

Vega Cantor, R. (2009). Crisis Civlizatoria. Herramienta $N^{\circ}$ 42: Revista de debate y critica marxista. Recuperado el 17 de marzo de 2017, de Crisis Civilizatoria: http://www.herramienta.com.ar/revista-herramienta-n-42/crisis-civilizatoria

Vega Cantor, R. (2012). Capitalismo y despojo: perspectiva histórica sobre la expropiación universal de bienes y saberes. Buenos Aires: impresol ediciones.

Vincent J., E. (1979). Breve historia de la primera guerra mundial. México: Editorial Diana S.A. 
Wallerstein, I. (1979). El moderno sistema mundial. La agricultura capitalista y los orígenes de la economía-mundo europea en el siglo XVI. Madrid: Siglo XXI Editores.

i 